\title{
Interactions of Bargaining Power and Introduction of Online Channel in Two Competing Supply Chains
}

\author{
Jie Wei $\mathbb{D}^{1},{ }^{1}$ Tong Shao, ${ }^{1}$ and Jing Zhao ${ }^{2}$ \\ ${ }^{1}$ School of Economics and Management, Hebei University of Technology, Tianjin 300401, China \\ ${ }^{2}$ School of Science, Tianjin Polytechnic University, Tianjin 300387, China \\ Correspondence should be addressed to Jie Wei; weijie2288@163.com
}

Received 28 June 2017; Revised 29 October 2017; Accepted 25 December 2017; Published 24 January 2018

Academic Editor: Asier Ibeas

Copyright (c) 2018 Jie Wei et al. This is an open access article distributed under the Creative Commons Attribution License, which permits unrestricted use, distribution, and reproduction in any medium, provided the original work is properly cited.

\begin{abstract}
This paper studies the effect of dual-channel format on supply chain's competition ability and the effect of different bargaining powers on the competition between two supply chains and the optimal pricing decisions of all supply chain members when one supply chain introduces an online retailing channel. We develop four game models and obtain the optimal pricing decisions in closed form of these models and give some sensitivity analysis through numerical approach. Some new managerial insights are obtained as follows: Regardless of the two supply chain members' bargaining forms, the optimal price, the maximal demand, and the maximal profit decrease as the self-price sensitivity decreases. The industry holds advantage in getting higher profit when the supply chain without online retailing channel is led by the retailer. In addition, we find that a manufacturer as a leader of its supply chain can get more profit when the competing supply chain's leader is the manufacturer than when the competing supply chain's leader is the retailer.
\end{abstract}

\section{Introduction}

In the past few years, the advent of Internet-based electronic commerce has significantly changed the environment of business and has increasingly changed consumers' consumption patterns and manufacturers' sale models. There are, in our real life, more and more manufacturers (e.g., Hewlett \& Packard, Pioneer Electronics, IBM, and Dell Computer) who are increasingly using a dual channel, a combination of the online and traditional channels, to distribute their products [1]. The online channel has helped manufacturers reach different consumer segments that cannot be reached by the traditional retail channel, control sale price, and increase profits. On the other hand, consumers also have become accustomed to purchasing products through online channel; the online channel means more shopping choices and price savings for consumers.

So far, most published researches on online channel supply chain have focused on a single supply chain with one manufacturer and one retailer (i.e., [2-5]). In these studies, a single manufacturer distributes products through a dual channel. However, in our real life, with the technology development and the economy globalization, competition exists not only among different supply chain members, but also at the supply chain level, resulting in the chain-tochain competition in many industries. For example, in the telecommunication industry, where the supply chains are differentiated by technologies, Microsoft and HTC may form a supply chain which competes with the supply chain with Symbian and Nokia. Other examples include the car manufacturing and retailing and crude oil and gasoline industries. Obviously, with this competition, either an upstream firm or a downstream firm in one supply chain not only competes against his/her corresponding firm in the other supply chain, but also competes against the whole other chain. Moreover, if one supply chain introduces an online channel, can the dual-channel format increase the supply chain's competition ability? Can the manufacturer increase its profit by introducing an online channel? How does different bargaining powers of supply chain members affect the competition between two supply chains and the optimal pricing of all supply chain members when one supply chain introduces an online channel? To the best of our knowledge, no research has considered these problems. There are both academic and 
practical values to consider these problems and this is an interesting topic focused by managers. The aim of this paper is to explore the above problems.

Specifically, in this paper, we consider two supply chains which compete in the market with two substitutable products. Each supply chain includes one manufacturer and one retailer. Each manufacturer produces one product, and the two manufacturers' products are substitutable. Moreover, assume one of the two supply chains is a traditional supply chain where the manufacturer sells a product to the retailer, while the other supply chain has adopted an online channel where the manufacturer sells its product to the retailer, as well as to the end customers directly. We formulate four game models to characterize the competition between the two supply chains when one supply chain introduces an online channel. The bargaining powers between each supply chain are considered, and the solutions of these models are also obtained. We also perform the sensitivity analysis through numerical studies of some key parameters for examining their influences on the supply chain members' optimal pricing and maximal profits. On the basis of comparison and analysis of solutions of these models, some new managerial insights are derived. Our findings show that, regardless of the two supply chain members' bargaining forms, the optimal prices, the maximal demands, and the maximal profits decrease with decreasing values of self-price sensitivity. The industry holds advantage in getting the higher profit when the supply chain without online channel is led by the retailer. In addition, we find that a manufacturer that is a leader in its supply chain can get more profit when the competing supply chain's leader is the manufacturer than when the competing supply chain's leader is the retailer.

This research is related to the literature rooted in the dual channels. In the last few years, dual-channel supply chain has gained much attention from the supply chain management research community, and quite a large number of researches have been done about it, reviewed by Tsay and Agrawal [1] and by Cattani et al. [6]. For example, Chen et al. [7] studied a manufacturer's problem of managing his online sales channel together with an independently owned bricksand-mortar retail channel, when the channels compete in service. Cai et al. [8] discussed a manufacturer's distribution strategy by focusing on different cost structures between the two channels and showed that a manufacturer uses both channels when online channel cost is not very high. Yao and Liu [3] showed that introducing an online channel not only generates competitive pricing and payoffs, but also encourages cost effective retails services. Batarfi et al. [9] investigated the effect of adopting a dual channel on the performance of a two-level supply chain; their results show that adding a customized-product online channel would increase the profit of the centralized supply chain system. Huang and Swaminathan [10] and Khouja et al. [11] studied the optimal pricing strategy when a retailer sells its product though an dual channel. Schneider and Klabjan [12] analyzed conditions for known inventory control policies to be optimal in presence of two different sales channels. Yang et al. [13] considered the inventory competition of perishable products in a dual-channel supply chain with consideration of the delivery lead time in the online channel. Differing from those of prior studies, the focus of this research is to study how the dual-channel format affects the supply chain's competition ability facing different bargaining powers of two competing supply chains.

Our research is also related to the literature rooted in the chain-to-chain competition. There is little literature that examines the chain-to-chain competition. For example, $\mathrm{Wu}$ et al. [14] investigated the equilibrium behavior of two competing supply chains in the presence of demand uncertainty. Anderson and Bao [15] considered the chainto-chain competition in which different manufacturers sell through exclusive retailers that compete for end customers. Trivedi [16] found that the competitions at both retailer and manufacturer levels have significant impacts on the members' profits and prices. Wei and Zhao [17] study the pricing and remanufacturing decisions of two competing supply chains with competition at both manufacturer and retailer levels. McGuire and Staelin [18] considered two competing supply chains where each manufacturer must decide whether to integrate into retailing or sell its products through an exclusive retailer via a wholesale-price contract. Coughlan [19] extended the research of McGuire and Staelin [18] to a more general demand function and applied it to the international semiconductor industry. However, to the best of our knowledge, no research has studied how the dual-channel format affects the chain-to-chain competition through considering the bargaining powers of two competing supply chains. Our paper tries to fill this research gap.

The remainder of this paper is organized as follows. Section 2 introduces the problem description. Four pricing models and the corresponding analytical results are discussed in Section 3. In Section 4, we report the comparisons and managerial implications of the results obtained in this article. We conclude the results and suggest topics for future research in Section 5.

\section{Problem Description}

Consider two supply chains (supply chain 1 and supply chain 2) which compete in the market with two substitutable products (product 1 and product 2). Supply chain 1 includes manufacturer 1 and retailer 1 , and supply chain 2 contains manufacturer 2 and retailer 2 . In the following discussion, "he" represents one of the two manufacturers, and "she" represents one of the two retailers. Manufacturer 1 produces a product (product 1) with unit manufacturing cost $c_{1}$ and wholesales it to retailer 1 with unit wholesale price $w_{1}$ and sells the product to consumers directly through an online store with unit retail price $p_{0}$. Manufacturer 2 produces a product (product 2) with unit manufacturing cost $c_{2}$ and only wholesales it to retailer 2 with unit wholesale price $w_{2}$. Retailer $i$ then sells the product $i$ to the end consumer with unit retail price $p_{i}, i=1,2$. Products 1 and 2 are substitutable. Manufacturer 1 must determine the wholesale price $w_{1}$ for product 1 to the retailer and the retail price $p_{0}$ for product 1 to consumers directly from his online store. Manufacturer 2 must determine the wholesale price $w_{2}$ for product 2 to the retailer. The retailer $i$ must determine the retail price 
$p_{i}$ for product $i$. We assume that the channel members are independent and risk-neutral and all channel members have complete information of the demands and the cost structures.

Linear demand functions of retail prices are used to characterize market demand because linear demand functions are tractable and commonly adopted in the literature on supply chain analysis $[16,18,20-23]$. We assume that the market demand $D_{0}$ for product 1 , sold through manufacturer 1's online channel, is given as

$$
D_{0}=a-\beta_{0} p_{0}+\beta_{1}\left(p_{1}-p_{0}\right)+\beta_{2}\left(p_{2}-p_{0}\right) \text {. }
$$

The demand $D_{1}$ for product 1 , sold through the traditional channel, is denoted as

$$
D_{1}=a-\beta_{0} p_{1}+\beta_{1}\left(p_{0}-p_{1}\right)+\beta_{3}\left(p_{2}-p_{1}\right),
$$

and the demand $D_{2}$ for product 2, sold through the traditional channel, is denoted as

$$
D_{2}=a-\beta_{0} p_{2}+\beta_{3}\left(p_{1}-p_{2}\right)+\beta_{2}\left(p_{0}-p_{2}\right),
$$

where the parameter $a$ represents the market base of each demand $D_{i}, i=0,1,2$. For expositional simplicity, we assume each channel has the same market base. The parameter $\beta_{0}$ is self-price elastic coefficient and $\beta_{1}, \beta_{2}, \beta_{3}$ are the cross-price elastic coefficients.

According to the above description, we can formulate the members' profit functions as follows. The two retailers' profit functions are

$$
\begin{aligned}
\pi_{r 1} & =\left(p_{1}-w_{1}\right) \\
& \cdot\left(a-\beta_{0} p_{1}+\beta_{1}\left(p_{0}-p_{1}\right)+\beta_{3}\left(p_{2}-p_{1}\right)\right), \\
\pi_{r 2} & =\left(p_{2}-w_{2}\right) \\
& \cdot\left(a-\beta_{0} p_{2}+\beta_{3}\left(p_{1}-p_{2}\right)+\beta_{2}\left(p_{0}-p_{2}\right)\right) .
\end{aligned}
$$

Manufacturer 1's profit function is

$$
\begin{aligned}
\pi_{m 1} & =\left(w_{1}-c_{1}\right) \\
& \cdot\left(a-\beta_{0} p_{1}+\beta_{1}\left(p_{0}-p_{1}\right)+\beta_{3}\left(p_{2}-p_{1}\right)\right) \\
+ & \left(p_{0}-c_{1}\right) \\
& \cdot\left(a-\beta_{0} p_{0}+\beta_{1}\left(p_{1}-p_{0}\right)+\beta_{2}\left(p_{2}-p_{0}\right)\right) .
\end{aligned}
$$

Manufacturer 2's profit function is

$$
\begin{aligned}
& \pi_{m 2} \\
& =\left(w_{2}-c_{2}\right)\left(a-\beta_{0} p_{2}+\beta_{3}\left(p_{1}-p_{2}\right)+\beta_{2}\left(p_{0}-p_{2}\right)\right) .
\end{aligned}
$$

\section{Analytical Results}

In this section, in order to investigate the effect of bargaining powers of supply chain members on the profits and decisions of the supply chain participants and to explore which particular organization structure of the two supply chains is appropriate for one of the two competing manufacturers to open an online channel, we consider the case where the two supply chains are decentralized and establish the corresponding decision model and allow for the competition in each supply chain to be modeled as a Stackelberg game. Such modeling enables us to capture the supply chain members' competitive dynamics under four power structures. Specifically, the decentralized decision models are listed in Table 1.

The leader in every decision scenario makes its decision to maximize its own profit, conditioned on the follower's response. The problem is solved backwards. Namely, the decision of the follower is solved first, given that the leader's decision has been observed.

3.1. The MOMT Model. The MOMT model arises in the markets where two retailers retail two substitutable products (e.g., computers), and each retailer's power is smaller compared to her manufacturer's. For example, manufacturer 1 (e.g., Dell who has used a combination of the traditional and online channels to retail its computer) plays a more dominant role than his small- and medium-sized agents, and manufacturer 2 (e.g., Lenovo) plays a more dominant role than her retailer. In these real-world supply chains, the manufacturers will act as the Stackelberg leaders and the retailers will act as the Stackelberg followers in their own supply chains. So, in this case, the two manufacturers first make their decisions simultaneously and the two retailers then make their decisions simultaneously. Specifically, manufacturer 1 announces the wholesale price $w_{1}$ and the retail price $p_{0}$, and manufacturer 2 announces the wholesale price $w_{2}$ simultaneously; then retailer 1 announces the retail price $p_{1}$ and the retailer 2 announces the retail price $p_{2}$ simultaneously. The MOMT model is given as follows:

$$
\begin{gathered}
\max _{w_{1}, p_{0}} \pi_{m 1}\left(w_{1}, p_{0}, p_{1}^{*}\left(w_{1}, w_{2}, p_{0}\right), p_{2}^{*}\left(w_{1}, w_{2}, p_{0}\right)\right) . \\
\max _{w_{2}} \pi_{m 2}\left(w_{2}, p_{1}^{*}\left(w_{1}, w_{2}, p_{0}\right), p_{2}^{*}\left(w_{1}, w_{2}, p_{0}\right)\right) \\
p_{1}^{*}\left(w_{1}, w_{2}, p_{0}\right), p_{2}^{*}\left(w_{1}, w_{2}, p_{0}\right) \text { are derived from solving the following problem } \\
\max _{p_{1}} \pi_{r 1}\left(p_{1}\right) \\
\max _{p_{2}} \pi_{r 2}\left(p_{2}\right)
\end{gathered}
$$


TABLE 1: Bargaining power structures and the corresponding models.

\begin{tabular}{lc}
\hline Model & Bargaining power structure \\
\hline MOMT model & Two manufacturers are the leaders \\
RORT model & Two retailers are the leaders \\
MORT model & Manufacturer 1 and retailer 2 are the leaders \\
ROMT model & Retailer 1 and manufacturer 2 are the leaders \\
\hline
\end{tabular}

So, we first derive the two retailers' decisions as follows. Given earlier decisions $w_{1}, p_{0}$, and $w_{2}$ made by the two manufacturers, respectively, we can derive the two retailers' best response functions, by setting $\partial \pi_{r 1} / \partial p_{1}$ and $\partial \pi_{r 2} / \partial p_{2}$ to zero and solving for $p_{1}$ and $p_{2}$ simultaneously, as follows:

$$
\begin{aligned}
p_{1}^{*}\left(w_{1}, w_{2}, p_{0}\right) & \frac{2\left(\beta_{0}+\beta_{1}+\beta_{3}\right)\left(\beta_{0}+\beta_{2}+\beta_{3}\right)}{4\left(\beta_{0}+\beta_{1}+\beta_{3}\right)\left(\beta_{0}+\beta_{2}+\beta_{3}\right)-\beta_{3}^{2}} w_{1} \\
& +\frac{2 \beta_{1}\left(\beta_{0}+\beta_{2}+\beta_{3}\right)+\beta_{2} \beta_{3}}{4\left(\beta_{0}+\beta_{1}+\beta_{3}\right)\left(\beta_{0}+\beta_{2}+\beta_{3}\right)-\beta_{3}^{2}} p_{0} \\
& +\frac{\beta_{3}\left(\beta_{0}+\beta_{2}+\beta_{3}\right)}{4\left(\beta_{0}+\beta_{1}+\beta_{3}\right)\left(\beta_{0}+\beta_{2}+\beta_{3}\right)-\beta_{3}^{2}} w_{2} \\
& +\frac{2 a\left(\beta_{0}+\beta_{2}+\beta_{3}\right)+a \beta_{3}}{4\left(\beta_{0}+\beta_{1}+\beta_{3}\right)\left(\beta_{0}+\beta_{2}+\beta_{3}\right)-\beta_{3}^{2}}, \\
p_{2}^{*}\left(w_{1}, w_{2}, p_{0}\right) & \frac{2\left(\beta_{0}+\beta_{1}+\beta_{3}\right)\left(\beta_{0}+\beta_{2}+\beta_{3}\right)}{4\left(\beta_{0}+\beta_{1}+\beta_{3}\right)\left(\beta_{0}+\beta_{2}+\beta_{3}\right)-\beta_{3}^{2}} w_{2} \\
& +\frac{2 \beta_{2}\left(\beta_{0}+\beta_{1}+\beta_{3}\right)+\beta_{1} \beta_{3}}{4\left(\beta_{0}+\beta_{1}+\beta_{3}\right)\left(\beta_{0}+\beta_{2}+\beta_{3}\right)-\beta_{3}^{2}} p_{0} \\
& +\frac{\beta_{3}\left(\beta_{0}+\beta_{1}+\beta_{3}\right)}{4\left(\beta_{0}+\beta_{1}+\beta_{3}\right)\left(\beta_{0}+\beta_{2}+\beta_{3}\right)-\beta_{3}^{2}} w_{1} \\
& \left.\left.+\beta_{0}+\beta_{1}+\beta_{3}\right)+a \beta_{3}\right)\left(\beta_{0}+\beta_{2}+\beta_{3}\right)-\beta_{3}^{2}
\end{aligned}
$$

Having the information about the decisions of the two retailers, the two manufacturers would then use them to maximize their profits simultaneously. Substituting $p_{1}^{*}\left(w_{1}, w_{2}, p_{0}\right)$ and $p_{2}^{*}\left(w_{1}, w_{2}, p_{0}\right)$ in (9) into the two manufacturers' profit functions in (6) and (7), and applying the first-order conditions to the resulting profit functions in terms of the wholesale prices $w_{1}, w_{2}$ and the retail price $p_{0}$, we get manufacturer 1's wholesale price $w_{1}^{*}$ and retail price $p_{0}^{*}$ and manufacturer 2's wholesale price $w_{2}^{*}$, at equilibrium, as follows:

$$
\left(\begin{array}{c}
w_{1}^{*} \\
p_{0}^{*} \\
w_{2}^{*}
\end{array}\right)=\left(\begin{array}{lll}
A_{8} & A_{9} & A_{10} \\
A_{9} & A_{12} & A_{13} \\
A_{15} & A_{16} & A_{17}
\end{array}\right)^{-1}\left(\begin{array}{c}
A_{11} \\
A_{14} \\
A_{18}
\end{array}\right),
$$

where $A_{8}, A_{9}, \ldots, A_{18}$ are constants defined in Appendix A.
Hence, with (9)-(10), we can see that the two retailers' equilibrium retail prices in the MOMT model, denoted as $p_{1}^{*}$ and $p_{2}^{*}$, respectively, are

$$
\begin{aligned}
p_{1}^{*}= & \frac{2\left(\beta_{0}+\beta_{1}+\beta_{3}\right)\left(\beta_{0}+\beta_{2}+\beta_{3}\right)}{4\left(\beta_{0}+\beta_{1}+\beta_{3}\right)\left(\beta_{0}+\beta_{2}+\beta_{3}\right)-\beta_{3}^{2}} w_{1}^{*} \\
& +\frac{2 \beta_{1}\left(\beta_{0}+\beta_{2}+\beta_{3}\right)+\beta_{2} \beta_{3}}{4\left(\beta_{0}+\beta_{1}+\beta_{3}\right)\left(\beta_{0}+\beta_{2}+\beta_{3}\right)-\beta_{3}^{2}} p_{0}^{*} \\
& +\frac{\beta_{3}\left(\beta_{0}+\beta_{2}+\beta_{3}\right)}{4\left(\beta_{0}+\beta_{1}+\beta_{3}\right)\left(\beta_{0}+\beta_{2}+\beta_{3}\right)-\beta_{3}^{2}} w_{2}^{*} \\
& +\frac{2 a\left(\beta_{0}+\beta_{2}+\beta_{3}\right)+a \beta_{3}}{4\left(\beta_{0}+\beta_{1}+\beta_{3}\right)\left(\beta_{0}+\beta_{2}+\beta_{3}\right)-\beta_{3}^{2}}, \\
p_{2}^{*}= & \frac{2\left(\beta_{0}+\beta_{1}+\beta_{3}\right)\left(\beta_{0}+\beta_{2}+\beta_{3}\right)}{4\left(\beta_{0}+\beta_{1}+\beta_{3}\right)\left(\beta_{0}+\beta_{2}+\beta_{3}\right)-\beta_{3}^{2}} w_{2}^{*} \\
& +\frac{2 \beta_{2}\left(\beta_{0}+\beta_{1}+\beta_{3}\right)+\beta_{1} \beta_{3}}{4\left(\beta_{0}+\beta_{1}+\beta_{3}\right)\left(\beta_{0}+\beta_{2}+\beta_{3}\right)-\beta_{3}^{2}} p_{0}^{*} \\
& +\frac{\beta_{3}\left(\beta_{0}+\beta_{1}+\beta_{3}\right)}{4\left(\beta_{0}+\beta_{1}+\beta_{3}\right)\left(\beta_{0}+\beta_{2}+\beta_{3}\right)-\beta_{3}^{2}} w_{1}^{*} \\
& +\frac{2 a\left(\beta_{0}+\beta_{1}+\beta_{3}\right)+a \beta_{3}}{4\left(\beta_{0}+\beta_{1}+\beta_{3}\right)\left(\beta_{0}+\beta_{2}+\beta_{3}\right)-\beta_{3}^{2}},
\end{aligned}
$$

where $w_{1}^{*}, p_{0}^{*}$, and $w_{2}^{*}$ are defined as in (10).

Proposition 1. In the MOMT model, manufacturer 1's equilibrium wholesale price $w_{1}^{*}$ and equilibrium retail price $p_{0}^{*}$ are given in (10), manufacturer 2's equilibrium wholesale price $w_{2}^{*}$ is also given in (10), and the two retailers' equilibrium retail prices $p_{1}^{*}, p_{2}^{*}$ are given in (11) and (12), respectively.

Proof. Proof of Proposition 1, as well as the other remaining proofs of the propositions in this article, appears in Appendix C.

3.2. The RORT Model. The RORT model arises in the markets where two retailers retail two substitutable products (e.g., mobile phones), and each retailer's power is larger compared to her manufacturer's. For example, retailer 1 (e.g., Gome.com) plays a more dominant role than her supplier/manufacturer (e.g., Meizu), Meizu sells its mobile phone not only through Gome.com but also through its online store (https://www.meizu.com), and retailer 2 (e.g., Suning.com) plays a more dominant role than her supplier/manufacturer (e.g., k-touch). So, in this case, the two retailers first make their decisions simultaneously and the two manufacturers then make their decisions simultaneously. Specifically, retailer 1 announces the retail price $p_{1}$ and retailer 2 announces the retail price $p_{2}$ simultaneously and then manufacturer 1 announces the wholesale price $w_{1}$ and retail price $p_{0}$ and manufacturer 2 announces the wholesale price $w_{2}$ simultaneously. The RORT model is given as follows: 


$$
\begin{gathered}
\max _{p_{1}} \pi_{r 1}\left(p_{1}, w_{1}^{*}\left(p_{1}, p_{2}\right), w_{2}^{*}\left(p_{1}, p_{2}\right), p_{0}^{*}\left(p_{1}, p_{2}\right)\right) \\
\max _{p_{2}} \pi_{r 2}\left(p_{2}, w_{1}^{*}\left(p_{1}, p_{2}\right), w_{2}^{*}\left(p_{1}, p_{2}\right), p_{0}^{*}\left(p_{1}, p_{2}\right)\right) \\
w_{1}^{*}\left(p_{1}, p_{2}\right), w_{2}^{*}\left(p_{1}, p_{2}\right), p_{0}^{*}\left(p_{1}, p_{2}\right) \text { are derived from solving the following problem } \\
\max _{w_{1}, p_{0}} \pi_{m 1}\left(w_{1}, p_{0}\right) \\
\max _{w_{2}} \pi_{m 2}\left(w_{2}\right) .
\end{gathered}
$$

So, we first need to derive the two manufacturers' decisions. Given earlier decisions $p_{1}$ and $p_{2}$ made by the two retailers, respectively, we can have the two manufacturers' best response functions as in (14).

$$
\begin{aligned}
& w_{1}^{*}\left(p_{1}, p_{2}\right)=-p_{1}+B_{1} p_{2}+B_{2}, \\
& p_{0}^{*}\left(p_{1}, p_{2}\right)=B_{3} p_{2}+B_{4}, \\
& w_{2}^{*}\left(p_{1}, p_{2}\right)=B_{5} p_{1}+B_{6} p_{2}+B_{7},
\end{aligned}
$$

where $B_{1}, B_{2}, \ldots, B_{7}$ are constants defined in Appendix A.

Having the information about the two manufacturers' decisions, the two retailers would then use them to maximize their profits simultaneously. Substituting $w_{1}^{*}, w_{2}^{*}$, and $p_{0}^{*}$ in (14) into the two retailers' profit functions in (4) and (5) and applying the first-order conditions to the resulting profit functions in terms of the retail prices $p_{1}$ and $p_{2}$ give retailer 1 's retail price $p_{1}^{*}$ and retailer 2 's retail price $p_{2}^{*}$, at equilibrium as follows:

$$
\begin{aligned}
& p_{1}^{*}=\frac{B_{9} B_{13}-B_{10} B_{12}}{B_{8} B_{12}-B_{9} B_{11}}, \\
& p_{2}^{*}=\frac{B_{10} B_{11}-B_{8} B_{13}}{B_{8} B_{12}-B_{9} B_{11}},
\end{aligned}
$$

where $B_{8}, B_{9}, \ldots, B_{13}$ are constants defined in Appendix A.

With (14)-(16), we can have manufacturer 1's optimal wholesale price $w_{1}^{*}$ and optimal retail price $p_{0}^{*}$ and manufacturer 2's optimal wholesale price $w_{2}^{*}$ at equilibrium in the RORT model as follows:

$$
\begin{aligned}
& w_{1}^{*}=-p_{1}^{*}+B_{1} p_{2}^{*}+B_{2}, \\
& p_{0}^{*}=B_{3} p_{2}^{*}+B_{4}, \\
& w_{2}^{*}=B_{5} p_{1}^{*}+B_{6} p_{2}^{*}+B_{7},
\end{aligned}
$$

where $p_{1}^{*}, p_{2}^{*}$ are defined as in (15) and (16), respectively.

Proposition 2. In the RORT model, manufacturer 1's equilibrium wholesale price $w_{1}^{*}$ and retail prices $p_{0}^{*}$ are given in (17) and (18), respectively, manufacturer 2's equilibrium wholesale price $w_{2}^{*}$ is given in (19), and the two retailers' equilibrium retail prices $p_{1}^{*}$ and $p_{2}^{*}$ are given in (15) and (16), respectively.

3.3. The MORT Model. The MORT model arises in the markets where two retailers retail two substitutable products (e.g., mobile phones), and one retailer's power is smaller compared to her manufacturer's and the other retailer's power is larger compared to her manufacturer's. For example, HUAWEI, who has used a combination of the traditional and online channels to retail its mobile phones, plays a more dominant role than his small and medium-sized agents; however, retailer 2 (e.g., GOME.com) plays a more dominant role than her supplier/manufacturer (e.g., Meizu). So, in this decision case, manufacturer 1 is a leader and retailer 1 is a follower in chain 1 , and retailer 2 is a leader and manufacturer 2 is a follower in chain 2 . Both manufacturer 1 and retailer 2 first announce the wholesale price $w_{1}$, retail price $p_{0}$, and retail price $p_{2}$ simultaneously; then both retailer 1 and manufacturer 2 decide the retail price $p_{1}$ and the wholesale price $w_{2}$ to maximize their profits simultaneously. So, we first need to derive the decisions of retailer 1 and manufacturer 2 . The MORT model is given as follows:

$$
\begin{gathered}
\max _{w_{1}, p_{0}} \pi_{m 1}\left(w_{1}, p_{0}, p_{1}^{*}\left(w_{1}, p_{0}, p_{2}\right), w_{2}^{*}\left(w_{1}, p_{0}, p_{2}\right)\right) \\
\max _{p_{2}} \pi_{r 2}\left(p_{2}, p_{1}^{*}\left(w_{1}, p_{0}, p_{2}\right), w_{2}^{*}\left(w_{1}, p_{0}, p_{2}\right)\right) \\
p_{1}^{*}\left(w_{1}, p_{0}, p_{2}\right), w_{2}^{*}\left(w_{1}, p_{0}, p_{2}\right) \text { are derived from solving the following problem } \\
\max _{p_{1}} \pi_{r 1}\left(p_{1}\right) \\
\max _{w_{2}} \pi_{m 2}\left(w_{2}\right) .
\end{gathered}
$$


Given earlier decisions $p_{2}, w_{1}$, and $p_{0}$ made by retailer 2 and manufacturer 1 , respectively, we can derive the best response functions of manufacturer 2 and retailer 1 , by setting $\partial \pi_{r 1} / \partial p_{1}, \partial \pi_{m 2} / \partial w_{2}$ to zero and solving for $p_{1}$ and $w_{2}$ simultaneously, as follows:

$$
\begin{aligned}
& p_{1}^{*}(\left.w_{1}, p_{0}, p_{2}\right) \\
&= \frac{w_{1}}{2}+\frac{\beta_{1}}{2\left(\beta_{0}+\beta_{1}+\beta_{3}\right)} p_{0}+\frac{\beta_{3}}{2\left(\beta_{0}+\beta_{1}+\beta_{3}\right)} p_{2} \\
&+\frac{a}{2\left(\beta_{0}+\beta_{1}+\beta_{3}\right)}, \\
& w_{2}^{*}\left(w_{1}, p_{0}, p_{2}\right) \\
&=\frac{\beta_{3}}{2\left(\beta_{0}+\beta_{2}+\beta_{3}\right)} w_{1} \\
& \quad+\frac{2 \beta_{2}\left(\beta_{0}+\beta_{1}+\beta_{3}\right)+\beta_{1} \beta_{3}}{2\left(\beta_{0}+\beta_{1}+\beta_{3}\right)\left(\beta_{0}+\beta_{2}+\beta_{3}\right)} p_{0} \\
& \quad+\frac{\beta_{3}^{2}-2\left(\beta_{0}+\beta_{1}+\beta_{3}\right)\left(\beta_{0}+\beta_{2}+\beta_{3}\right)}{2\left(\beta_{0}+\beta_{1}+\beta_{3}\right)\left(\beta_{0}+\beta_{2}+\beta_{3}\right)} p_{2} \\
& \quad+\frac{a \beta_{3}+2 a\left(\beta_{0}+\beta_{1}+\beta_{3}\right)}{2\left(\beta_{0}+\beta_{1}+\beta_{3}\right)\left(\beta_{0}+\beta_{2}+\beta_{3}\right)}+c_{2} .
\end{aligned}
$$

Having the information about the decisions of manufacturer 2 and retailer 1 , retailer 2 and manufacturer 1 would then use them to maximize their profits simultaneously. Substituting $p_{1}$ and $w_{2}$ in (21) into the profit functions of retailer 2 and manufacturer 1 in (5) and (6) and applying the first-order condition to the resulting profit functions in terms of the $p_{2}, w_{1}$, and $p_{0}$ give retailer 2 's retail price $p_{2}^{*}$ and manufacturer 1's wholesale price $w_{1}^{*}$ and retail price $p_{0}^{*}$ as follows:

$$
\begin{aligned}
\left(\begin{array}{c}
w_{1}^{*} \\
p_{0}^{*} \\
p_{2}^{*}
\end{array}\right)= & \left(\begin{array}{ccc}
-\left(\beta_{0}+\beta_{1}+\beta_{3}\right) & \beta_{1} & \frac{\beta_{3}}{2} \\
\beta_{1} & E_{5} & E_{6} \\
E_{8} & E_{9} & E_{10}
\end{array}\right)^{-1} \\
& \cdot\left(\begin{array}{c}
-\frac{a+c_{1}\left(\beta_{0}+\beta_{3}\right)}{2} \\
-E_{7} \\
-E_{11}
\end{array}\right)
\end{aligned}
$$

where $E_{5}, E_{6}, \ldots, E_{11}$ are constants defined in Appendix A.
From (21)-(22), we can have manufacturer 2's optimal wholesale price $w_{2}^{*}$ and retailer 1's optimal retail price $p_{1}^{*}$ in the MORT model as follows:

$$
\begin{aligned}
p_{1}^{*}= & \frac{w_{1}}{2}+\frac{\beta_{1}}{2\left(\beta_{0}+\beta_{1}+\beta_{3}\right)} p_{0}^{*} \\
& +\frac{\beta_{3}}{2\left(\beta_{0}+\beta_{1}+\beta_{3}\right)} p_{2}^{*}+\frac{a}{2\left(\beta_{0}+\beta_{1}+\beta_{3}\right)}, \\
w_{2}^{*}= & \frac{\beta_{3}}{2\left(\beta_{0}+\beta_{2}+\beta_{3}\right)} w_{1}^{*} \\
& +\frac{2 \beta_{2}\left(\beta_{0}+\beta_{1}+\beta_{3}\right)+\beta_{1} \beta_{3}}{2\left(\beta_{0}+\beta_{1}+\beta_{3}\right)\left(\beta_{0}+\beta_{2}+\beta_{3}\right)} p_{0}^{*} \\
& +\frac{\beta_{3}^{2}-2\left(\beta_{0}+\beta_{1}+\beta_{3}\right)\left(\beta_{0}+\beta_{2}+\beta_{3}\right)}{2\left(\beta_{0}+\beta_{1}+\beta_{3}\right)\left(\beta_{0}+\beta_{2}+\beta_{3}\right)} p_{2}^{*} \\
& +\frac{a \beta_{3}+2 a\left(\beta_{0}+\beta_{1}+\beta_{3}\right)}{2\left(\beta_{0}+\beta_{1}+\beta_{3}\right)\left(\beta_{0}+\beta_{2}+\beta_{3}\right)}+c_{2},
\end{aligned}
$$

where $p_{2}^{*}, w_{1}^{*}$, and $p_{0}^{*}$ are defined as in (22).

Proposition 3. In the MORT model, manufacturer 1 's equilibrium wholesale price $w_{1}^{*}$ and equilibrium retail price $p_{0}^{*}$ are given in (22), manufacturer 2's equilibrium wholesale price $w_{2}^{*}$ is given in (24), retailer 1's equilibrium retail price $p_{1}^{*}$ is given in (23), and retailer 2's equilibrium retail price $p_{2}^{*}$ is given in (22).

3.4. The ROMT Model. The ROMT model arises in the markets where two retailers retail two substitutable products (e.g., mobile phones), and one retailer's (retailer 1) power is larger compared to her manufacturer's (manufacturer 1 that has used a combination of the traditional and online channels to retail its product) and the other retailer's (retailer 2) power is smaller compared to her manufacturer's. For example, retailer 1 (e.g., Gome.com) plays a more dominant role than her supplier/manufacturer (e.g., Meizu); however, manufacturer 2 (e.g., HUAWEI) plays a more dominant role than his small- and medium-sized agents. So, in this decision case, retailer 1 is a leader and manufacturer 1 is a follower in chain 1 , and manufacturer 2 is a leader and retailer 2 is a follower in chain 2. So, both manufacturer 2 and retailer 1 first announce the wholesale price $w_{2}$ and retail price $p_{1}$ simultaneously; then both retailer 2 and manufacturer 1 decide the retail price $p_{2}$, the wholesale price $w_{1}$, and the retail price $p_{0}$ to maximize their profits simultaneously. So, we first need to derive the decisions of retailer 2 and manufacturer 1 . The ROMT model is given as follows:

$$
\begin{gathered}
\max _{w_{2}} \pi_{m 2}\left(w_{2}, \tau, w_{1}^{*}\left(w_{2}, p_{1}\right), p_{0}^{*}\left(w_{2}, p_{1}\right), p_{2}^{*}\left(w_{2}, p_{1}\right)\right) \\
\max _{p_{1}} \pi_{r 1}\left(p_{1}, w_{1}^{*}\left(w_{2}, p_{1}\right), p_{0}^{*}\left(w_{2}, p_{1}\right), p_{2}^{*}\left(w_{2}, p_{1}\right)\right)
\end{gathered}
$$

$w_{1}^{*}\left(w_{2}, p_{1}\right), p_{0}^{*}\left(w_{2}, p_{1}\right), p_{2}^{*}\left(w_{2}, p_{1}\right)$ are derived from solving the following problem 


$$
\begin{gathered}
\max _{w_{1}, p_{0}} \pi_{m 1}\left(w_{1}, p_{0}\right) \\
\max _{p_{2}} \pi_{r 2}\left(p_{2}\right) .
\end{gathered}
$$

Given earlier decisions $w_{2}$ and $p_{1}$ made by manufacturer 2 and retailer 1 , respectively, we can derive the best response functions of manufacturer 1 and retailer 2 , by setting $\partial \pi_{m 1} / \partial w_{1}, \partial \pi_{m 1} / \partial p_{0}$, and $\partial \pi_{r 2} / \partial p_{2}$ to zero and solving for $w_{1}, p_{0}$, and $p_{2}$ simultaneously, as follows:

$$
\begin{aligned}
& p_{2}^{*}\left(w_{2}, p_{1}\right)=F_{1} p_{1}+F_{2} w_{2}+F_{3}, \\
& p_{0}^{*}\left(w_{2}, p_{1}\right)=F_{4} p_{1}+F_{5} w_{2}+F_{6}, \\
& w_{1}^{*}\left(w_{2}, p_{1}\right)=F_{7} p_{1}+F_{8} w_{2}+F_{9},
\end{aligned}
$$

where $F_{1}, F_{2}, \ldots, F_{9}$ are constants defined in Appendix A.

Having the information about the decisions of manufacturer 1 and retailer 2 , retailer 1 and manufacturer 2 would then use them to maximize their profits simultaneously. Substituting $w_{1}, p_{0}$, and $p_{2}$ in (26) into the profit functions of retailer 1 and manufacturer 2 in (4) and (7) and applying the first-order condition to the resulting profit functions in terms of $p_{1}$ and $w_{2}$ give retailer 1's retail price $p_{1}^{*}$ and manufacturer 2's wholesale price $w_{2}^{*}$ as follows:

$$
\begin{aligned}
& p_{1}^{*}=\frac{F_{11} F_{15}-F_{12} F_{14}}{F_{10} F_{14}-F_{11} F_{13}}, \\
& w_{2}^{*}=\frac{F_{13} F_{12}-F_{10} F_{15}}{F_{10} F_{14}-F_{11} F_{13}},
\end{aligned}
$$

where $F_{10}, F_{11}, \ldots, F_{15}$ are constants defined in Appendix A.

From (26)-(28), we can have manufacturer 1's optimal wholesale price $w_{1}^{*}$ and optimal wholesale price $p_{0}^{*}$ and retailer 2's optimal retail price $p_{2}^{*}$ in the ROMT model as follows:

$$
\begin{aligned}
& p_{2}^{*}=F_{1} p_{1}^{*}+F_{2} w_{2}^{*}+F_{3}, \\
& p_{0}^{*}=F_{4} p_{1}^{*}+F_{5} w_{2}^{*}+F_{6}, \\
& w_{1}^{*}=F_{7} p_{1}^{*}+F_{8} w_{2}^{*}+F_{9},
\end{aligned}
$$

where $p_{1}^{*}$ and $w_{2}^{*}$ are defined as in (27) and (28), respectively.

Proposition 4. In the ROMT model, manufacturer 1's equilibrium wholesale price $w_{1}^{*}$ and equilibrium retail price $p_{0}^{*}$ are given in (31) and (30), respectively, manufacturer 2's equilibrium wholesale price $w_{2}^{*}$ is given in (28), retailer 1 's equilibrium retail price $p_{1}^{*}$ is given in (27), and retailer 2 's equilibrium retail price $p_{2}^{*}$ is given in (29).

\section{Comparisons and Managerial Implications}

In this section, we consider the following case that parameters in four decision models established above are all symmetric; that is, $\beta_{1}=\beta_{2}=\beta_{3}$, and $c_{1}=c_{2}$, and denote $\beta_{1}=\beta$ and $c_{1}=c$. The reason for restricting the two substitutable products to have identical parameter values is to enable a comparison of three decision models and to gain more insights into the managerial implication. The asymmetry between the products creates problems during comparison of decision models [24, 25]. Thus, a comparison using simplified parameter structures can separate the effects of different competition strategies in the models from the effects of differences in each parameter.

4.1. Comparison and Analysis of the Equilibrium Solutions. Consider that it is very difficult to analyze the changes of equilibrium prices and channel members' equilibrium profits with the parameters $a, c, \beta_{0}$, and $\beta$ in the four decision models by analytic approach because the equilibrium solutions are complicated. So, in this subsection, we perform the sensitivity analysis through numerical studies of the parameters $a, c, \beta_{0}$, and $\beta$ for examining their influences on the equilibrium solutions and channel members' equilibrium profits. On the basis of comparison and analysis, some managerial insights are derived. In the following numerical examples, the information on the parameter values is obtained from the existing numerical studies [26].

Discussion 1 (sensitivity analysis of the parameters $\beta$ and $\beta_{0}$ ). First, we explore how the optimal retail prices, wholesale prices, maximal demands, and the chain members' maximal profits are affected by changes in the cross-price sensitivity $\beta$. Figures 1-3 show the changes of the optimal prices, maximal demands, and the supply chain members' maximal profits with the parameter $\beta$ in the MOMT model, where default values of parameters are $a=200, c=3, \beta_{0}=8$, and $\beta \in\{2.3,2.6,2.9,3.2,3.5\}$.

Next, the mechanism by which the optimal retail prices, wholesale prices, maximal demands, and the maximal profits are affected by the changes in the self-price sensitivity $\beta_{0}$ is investigated. Figures $4-6$ present the changes of the optimal prices, maximal demands, and the chain members' maximal profits with the parameter $\beta_{0}$ in the MOMT model, where the parameters values are $a=200, c=3, \beta=2$, and $\beta_{0} \in$ $\{9,10,11,12,13\}$.

It follows from Figures 1-6 that the optimal wholesale prices and the optimal retail prices all decrease in the crossprice sensitivity $\beta$ and all decrease in the self-price sensitivity $\beta_{0}$ in the MOMT model. The maximal demands (i.e., $D_{0}^{*}, D_{1}^{*}$, and $D_{2}^{*}$ ), and the supply chain members' maximal profits (i.e., $\pi_{m 1}^{*}, \pi_{m 2}^{*}$, and $\pi_{r 2}^{*}$ ) all increase in the cross-price sensitivity $\beta$ in the MOMT model, whereas retailer 1's maximal profit (i.e., $\pi_{r 1}^{*}$ ) decreases in the cross-price sensitivity $\beta$ in the MOMT model. This means that as the cross-price sensitivity increases, although the marginal profits for manufacturer 1 , manufacturer 2 , and retailer 2 decrease, the increase of maximal demands makes the three players' profits increase. Namely, for manufacturer 1 , manufacturer 2, and retailer 2 


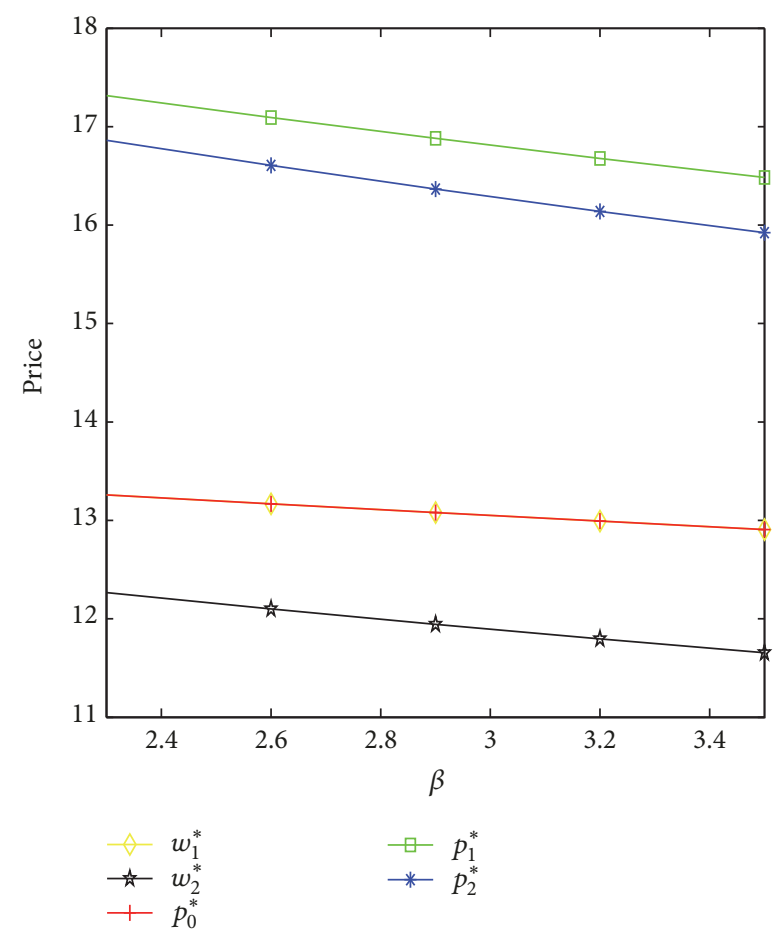

Figure 1: Changes of optimal prices with parameter $\beta$ in MOMT model.

in the MOMT model, the decrease of marginal profit can be offset by the revenue from increasing demand. Moreover, the maximal demands (i.e., $D_{0}^{*}, D_{1}^{*}$, and $D_{2}^{*}$ ), and the supply chain members' maximal profits (i.e., $\pi_{m 1}^{*}, \pi_{m 2}^{*}, \pi_{r 1}^{*}$, and $\pi_{r 2}^{*}$ ) all decrease in the self-price sensitivity $\beta_{0}$ in the MOMT model. Similarly, the same results can be obtained in the other three decision models, and the details are not discussed in this article, from which we can have the following managerial insight. Regardless of the two supply chain members' bargaining forms, the optimal prices, the maximal demands, and the maximal profits decrease with decreasing values of self-price sensitivity $\beta_{0}$.

Discussion 2 (sensitivity analysis of the parameters $a$ and c). First, the mechanism by which the optimal retail prices, wholesale prices, maximal demands, and the chain members' maximal profits are affected by the changes in the manufacturing cost $c$ is investigated. Figures 7-9 present the changes of the optimal prices, maximal demands, and the chain members' maximal profits with the parameter $c$ in the MOMT model, where default values of parameters are $a=$ $200, \beta_{0}=6, \beta=2$, and $c \in\{3,4,5,6,7\}$.

Second, we explore how the optimal prices, maximal demands, and the supply chain members' maximal profits are affected by changes in the market base $a$. Figures 10-12 present the changes of the optimal prices, maximal demands, and the supply chain members' maximal profits with parameter $a$ in the MOMT model, where the parameters values are $c=3, \beta_{0}=6, \beta=2$, and $a \in\{101,102,103,104,105\}$.

It follows from Figures 7-12 that the optimal wholesale prices and the optimal retail prices all increase in $c$, whereas

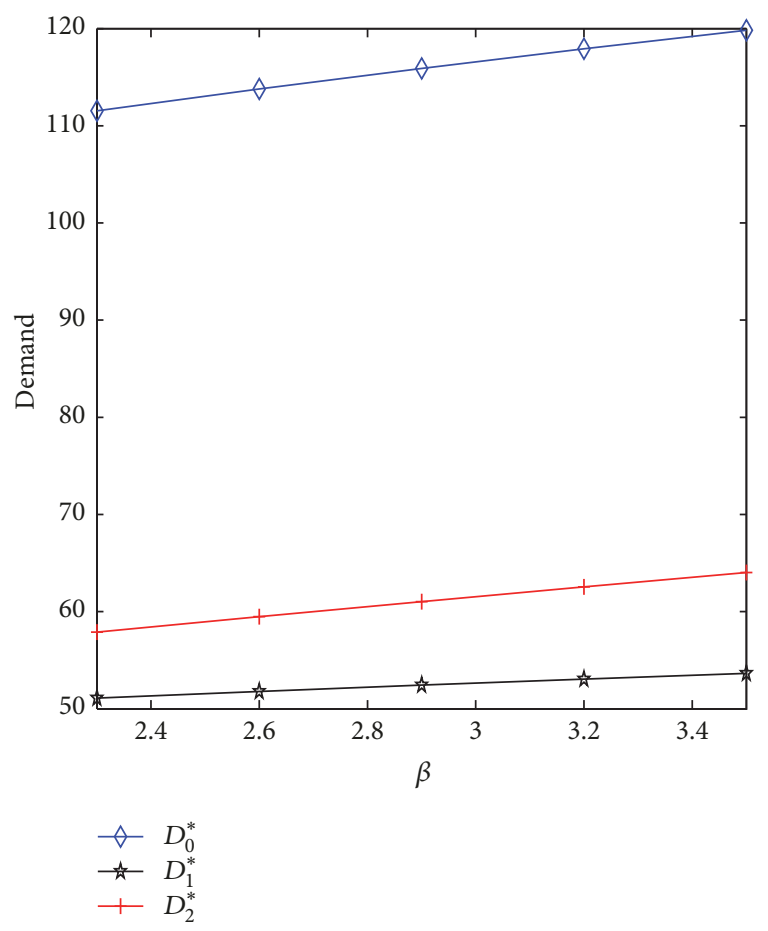

Figure 2: Changes of maximal demands with parameter $\beta$ in MOMT model.

the maximal demands (i.e., $D_{0}^{*}, D_{1}^{*}$, and $D_{2}^{*}$ ) and the supply chain members' maximal profits (i.e., $\pi_{m 1}^{*}, \pi_{m 2}^{*}, \pi_{r 1}^{*}$, and $\pi_{r 2}^{*}$ ) all decrease in $c$ in the MOMT model. This shows that the increase of production cost will directly cause the increase of sale price and the decrease of maximal demands, which directly damages all players' profits. On the other hand, the optimal wholesale prices, the optimal retail prices, the maximal demands (i.e., $D_{0}^{*}, D_{1}^{*}$, and $D_{2}^{*}$ ), and the supply chain members' maximal profits (i.e., $\pi_{m 1}^{*}, \pi_{m 2}^{*}, \pi_{r 1}^{*}$, and $\pi_{r 2}^{*}$ ) all increase in $a$ in the MOMT model. This tells us that the increase of potential demand will benefit all supply chain members.

Remark 5. Discussions similar to those in Discussions 1 and 2 can be obtained in the other three models when the parameters $\beta, \beta_{0}, a$, and $c$ vary. For brevity, these graphs, discussions, and sensitivity analyses are not presented in this article.

4.2. Numerical Study. Due to the complicated form of the analytic results, in this subsection, we compare the analytical results obtained from the above four decision models using numerical approach and study the behavior of firms facing different channel bargaining structures. Consider the case where the default values of the model parameters are as follows: $a=200, \beta_{1}=\beta_{2}=\beta_{3}=2, \beta_{0}=6$, and $c_{1}=c_{2}=3$. The corresponding results are shown as in Tables $2-4$.

Discussion 3. From Table 2, we can have the following results.

(3.1) The total profit of supply chain 1 with online channel achieves the highest profit in the RORT model, followed by 
TABLE 2: Maximal profits in four decision models.

\begin{tabular}{lcccccc}
\hline Scenario & $\pi_{t}^{*}$ & $\pi_{m 1}^{*}+\pi_{r 1}^{*}$ & $\pi_{m 2}^{*}+\pi_{r 2}^{*}$ & $\pi_{m 1}^{*}$ & $\pi_{m 2}^{*}$ & $\pi_{r 1}^{*}$ \\
\hline MOMT & $3.8496 \times 10^{3}$ & $2.6936 \times 10^{3}$ & $1.1559 \times 10^{3}$ & $2.4051 \times 10^{3}$ & 773.2242 & 288.4963 \\
RORT & $3.8500 \times 10^{3}$ & $2.7038 \times 10^{3}$ & $1.1462 \times 10^{3}$ & $2.1030 \times 10^{3}$ & 378.8258 & 600.8542 \\
MORT & $3.8506 \times 10^{3}$ & $2.7034 \times 10^{3}$ & $1.1471 \times 10^{3}$ & $2.4030 \times 10^{3}$ & 379.7971 & 300.3811 \\
ROMT & $3.8477 \times 10^{3}$ & $2.7010 \times 10^{3}$ & $1.1467 \times 10^{3}$ & $2.1001 \times 10^{3}$ & 767.7317 & 6000.8870 \\
\hline
\end{tabular}

Note. $\pi_{t}^{*}=\pi_{m 1}^{*}+\pi_{r 1}^{*}+\pi_{m 2}^{*}+\pi_{r 2}^{*}$.

TABLE 3: Maximal demands in four decision models.

\begin{tabular}{lccr}
\hline Scenario & $D_{0}^{*}$ & $D_{1}^{*}$ & $D_{2}^{*}$ \\
\hline MOMT & 118.1661 & 53.7118 & 61.8633 \\
RORT & 120.5847 & 54.8112 & 61.5488 \\
MORT & 120.5755 & 54.8070 & 61.6277 \\
ROMT & 120.6461 & 54.5309 & 61.5635 \\
\hline
\end{tabular}

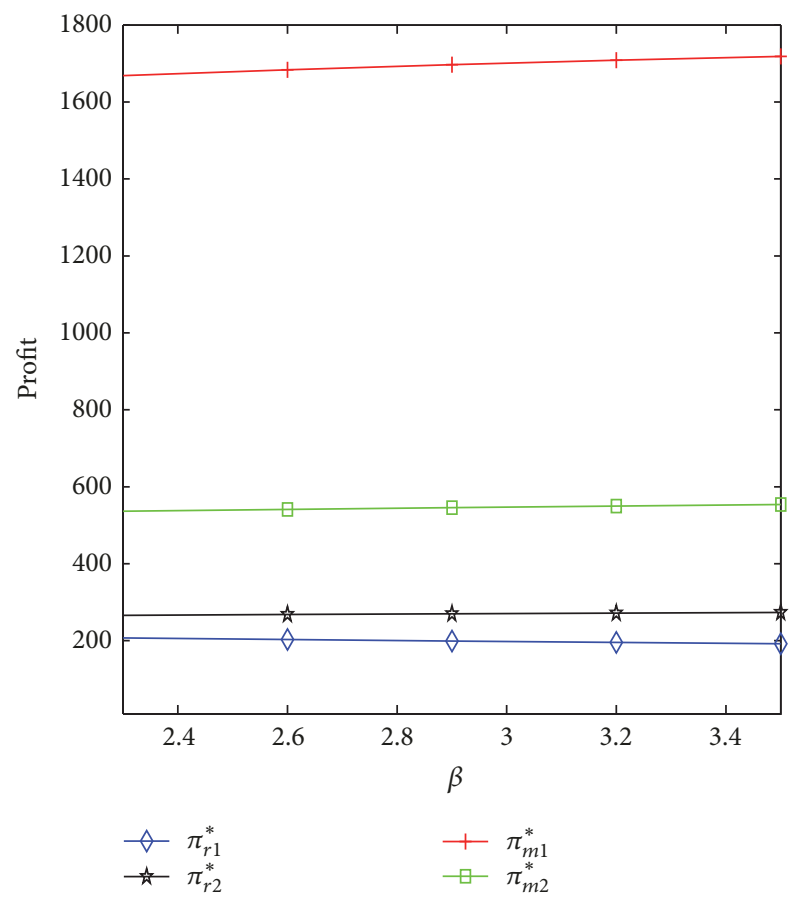

FIGURE 3: Changes of maximal profits with parameter $\beta$ in MOMT model.

the MORT model and then the ROMT model, and achieves the least profit in the MOMT model. On the other hand, the total profit of supply chain 2 without online channel achieves the highest profit in the MOMT model, followed by the MORT model and then the ROMT model, and achieves the least profit in the RORT model. This means that, for a given supply chain 2's channel power structure, the total profit of supply chain 1 under the case where retailer 1 is a leader in its supply chain is larger than under the case where retailer 1 is a follower in its supply chain. However, for given supply chain 1's channel power structure, the total profit of supply chain 2 under the case where retailer 2 is a leader of its supply chain is smaller than under the case where retailer 2 is a follower of supply chain 2. Moreover, the profit of the whole supply

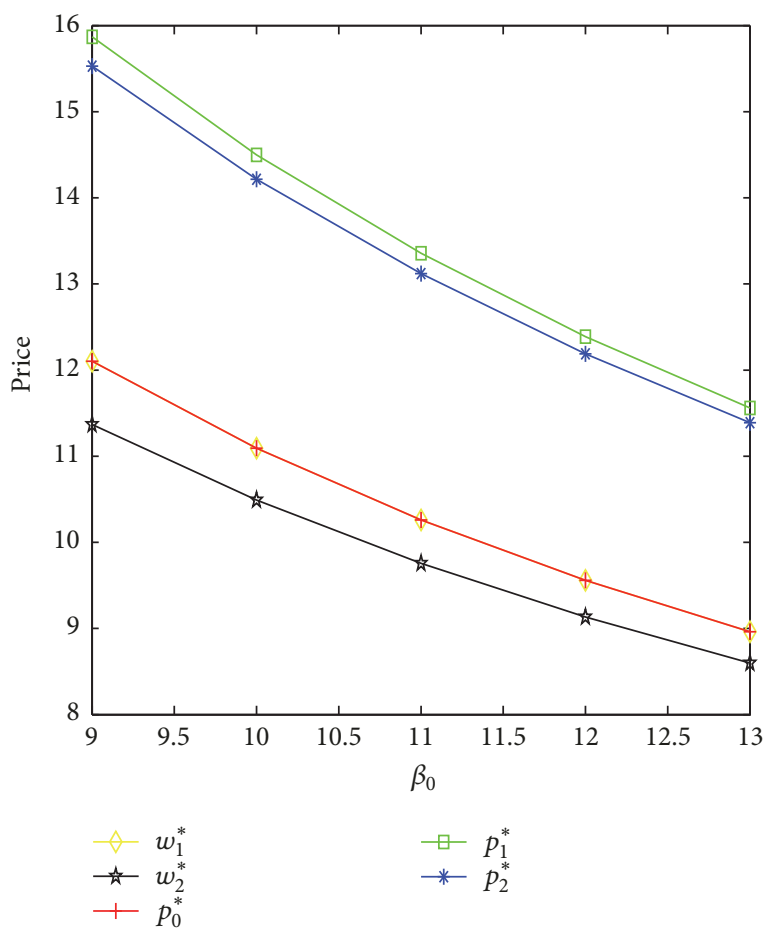

FIgURE 4: Changes of optimal prices with parameter $\beta_{0}$ in MOMT model.

chain 1 is always bigger than that of the whole supply chain 2 ; namely, the introduction of online channel for a supply chain can really increase its competition ability regardless of the two supply chains' bargaining structures.

(3.2) The industry profit achieves the highest profit in the MORT model, followed by the RORT model and then the MOMT model, and achieves the least profit in the ROMT model. This indicates that the industry holds advantage in getting the higher profit when the supply chain without online channel is led by the retailer.

(3.3) Comparing among the four decision cases, manufacturer 1 with online channel achieves his highest profit 
TABLE 4: Optimal prices in four decision models.

\begin{tabular}{lcccccccccc}
\hline Scenario & $p_{0}^{*}$ & $p_{0}^{*}-c$ & $p_{1}^{*}$ & $w_{1}^{*}$ & $w_{1}^{*}-c$ & $p_{1}^{*}-w_{1}^{*}$ & $p_{2}^{*}$ & $w_{2}^{*}$ & $w_{2}^{*}-c$ & $p_{2}^{*}-w_{2}^{*}$ \\
\hline MOMT & 16.9933 & 13.9933 & 22.3645 & 16.9933 & 13.9933 & 5.3712 & 21.6852 & 15.4989 & 12.4989 & 6.1863 \\
RORT & 16.7028 & 13.7028 & 22.1839 & 11.2217 & 8.2217 & 10.9622 & 21.6225 & 9.1549 & 6.1549 & 12.4676 \\
MORT & 16.7018 & 13.7018 & 22.1825 & 16.7018 & 13.7018 & 5.4807 & 21.6141 & 9.1628 & 6.1628 & 12.4513 \\
ROMT & 16.7034 & 13.7034 & 22.2130 & 11.1938 & 8.1938 & 10.0192 & 21.6269 & 15.4706 & 12.4706 & 6.1563 \\
\hline
\end{tabular}

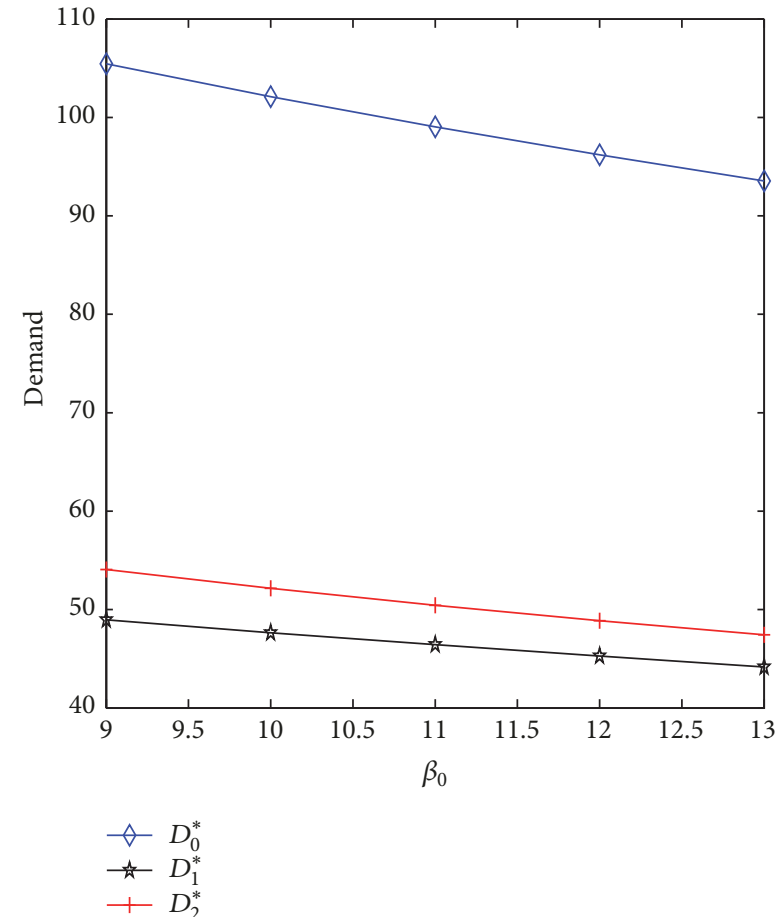

FIGURE 5: Changes of maximal demands with parameter $\beta_{0}$ in MOMT model.

in the MOMT model, followed by the MORT model and then the RORT model, and achieves the least profit in the ROMT model, whereas manufacturer 2 without online channel achieves his highest profit in the MOMT model, followed by the ROMT model and then the MORT model, and achieves the least profit in the RORT model. This means that the manufacturer $i$ holds advantage in getting the higher profit when he is a leader in the supply chain $i, i=1,2$, and the manufacturer $i$ who is a leader in the supply chain $i$ can get more profit when the competing chain's leader is the manufacturer $j$ than when the competing chain's leader is the retailer $j, i=1,2, j=3-i$.

(3.4) Comparing among the four decentralized decision cases, retailer 1 achieves her highest profit in the ROMT model, followed by the RORT model and then the MORT model, and achieves the least profit in the MOMT model, whereas retailer 2 achieves her highest profit in the RORT model, followed by the MORT model and then the MOMT model, and achieves the least profit in the ROMT model. This means that the retailer $i$ holds advantage in getting the higher profit when she is a leader in the supply chain $i, i=1,2$, and the retailer $i$ who is a leader in the supply chain $i$ can

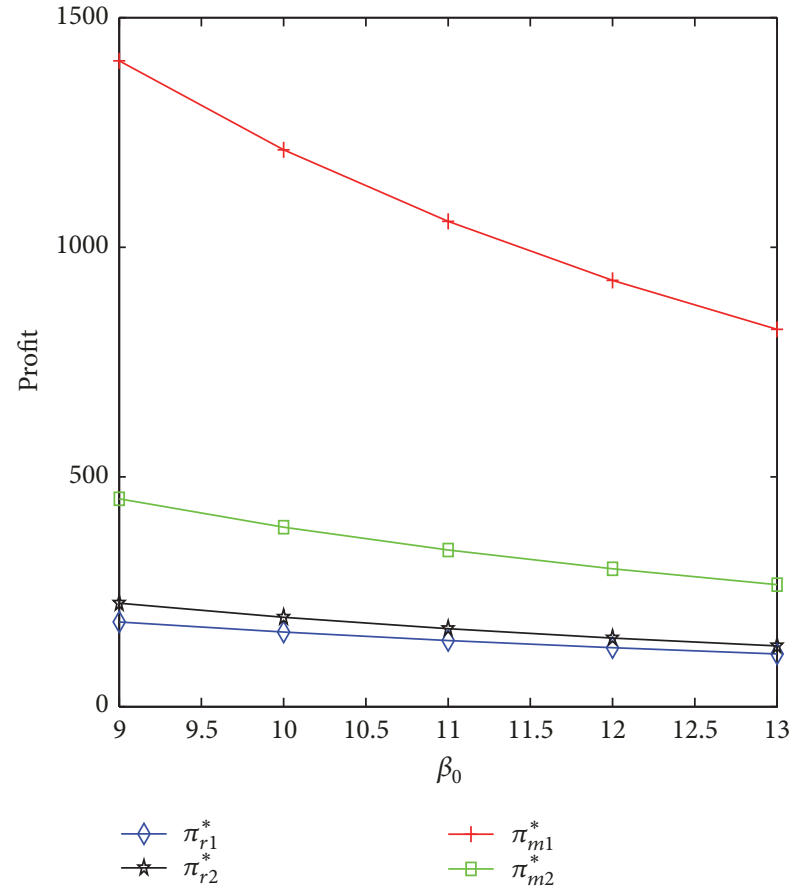

FIGURE 6: Changes of maximal profits with parameter $\beta_{0}$ in MOMT model.

get more profit when the competing supply chain's leader is the manufacturer $j$ than when the competing supply chain's leader is the retailer $j, i=1,2, j=3-i$.

(3.5) The profit of manufacturer 1 is always bigger than that of manufacturer 2 , which shows that manufacturer 1 can deeply strengthen its competition ability by adopting dual channel regardless of the two supply chains' bargaining structures. However, the profit of retailer 1 is smaller than that of retailer 2 except in the ROMT model; this means that the online channel introduced by a manufacturer does always benefit its retailer.

Discussion 4. From Table 3, the following results can be derived.

(4.1) The market demand $D_{0}$ for product 1 , sold through the online channel, achieves the smallest value in the MOMT model; this is followed by the MORT model and the RORT model, and the biggest value is obtained in the ROMT model, whereas the market demand $D_{1}$ for product 1 , sold through the traditional channel, achieves the smallest value in the MOMT model; this is followed by the ROMT model and the MORT model, and the biggest value is obtained in the RORT model. On the other hand, the market demand $D_{2}$ for 


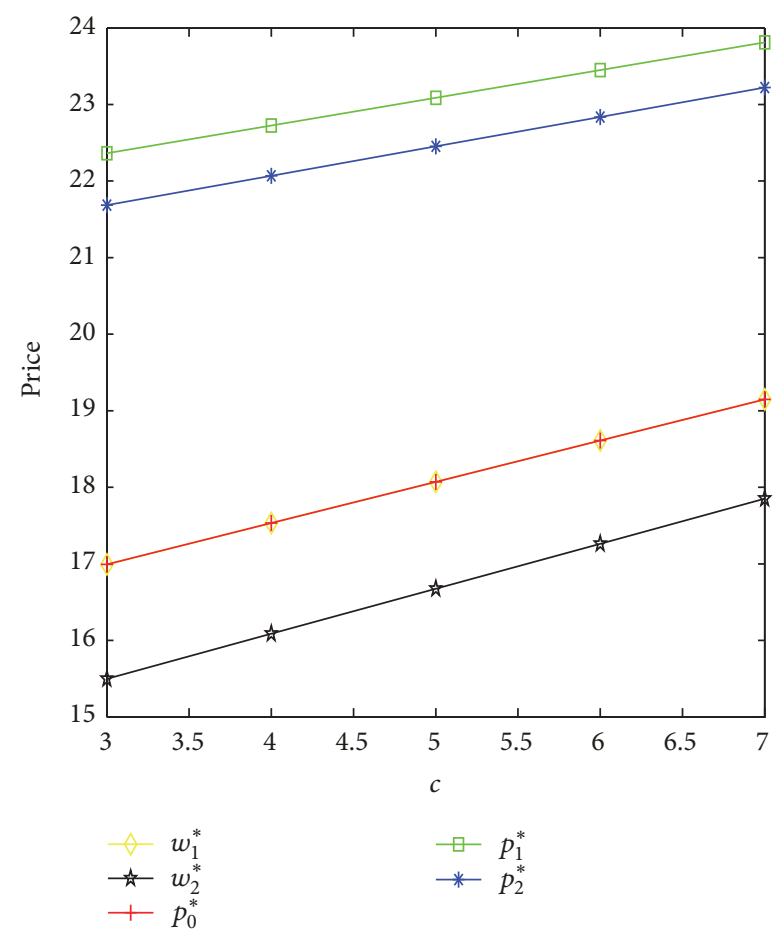

FIGURE 7: Changes of optimal prices with parameter $c$ in MOMT model.

product 2, sold through the traditional channel, achieves the smallest value in the RORT model; this is followed by the ROMT model and the MORT model, and the biggest value is obtained in the MOMT model. This indicates that both $D_{0}$ and $D_{1}$ achieve the biggest values in the MOMT model whereas $D_{2}$ achieves the smallest value in the MOMT model.

Discussion 5. From Table 4, the following results can be derived.

(5.1) The retail price $p_{0}$ for product 1 , sold through the online channel, achieves the smallest value in the MORT model; this is followed by the RORT model and the ROMT model, and the biggest value is obtained in the MOMT model. Moreover, the retail price $p_{1}$ for product 1 sold through the traditional channel and the retail price $p_{2}$ for product 2 sold through the traditional channel both have the same results as the retail price $p_{0}$ for product 1 sold through the online channel.

(5.2) The wholesale price $w_{1}$ for product 1 achieves the smallest value in the ROMT model; this is followed by the RORT model and the MORT model, and the biggest value is obtained in the MOMT model. However, the wholesale price $w_{2}$ for product 2 achieves the smallest value in the RORT model; this is followed by the MORT model and the ROMT model, and the biggest value is obtained in the MOMT model. This indicates that the two manufacturers will charge higher wholesale prices when they have leaderships in their own supply chains.

(5.3) Comparing among the four decision cases, the retailer $i$ will obtain the bigger profit margin from product $i$ when she has the leadership of chain $i$ and the manufacturer

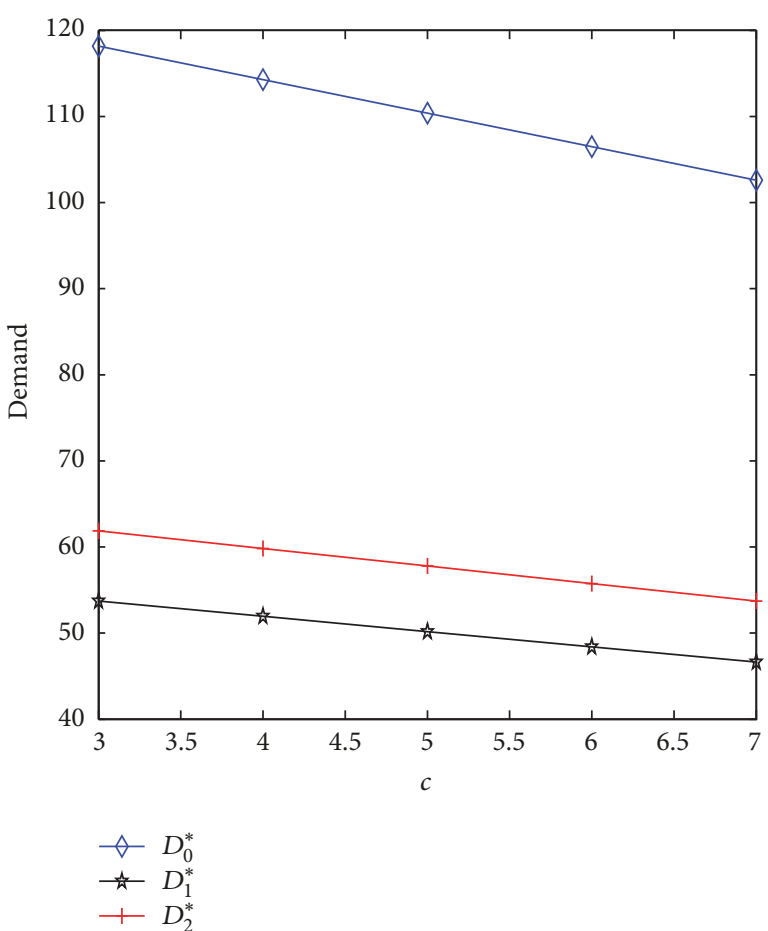

FIgURE 8: Changes of maximal demands with parameter $c$ in MOMT model.

$i$ will also obtain the bigger profit margin from product $i$ when he has the leadership of chain $i, i=1,2$. This indicates that a firm who is the leader of his/her supply chain has the advantage of getting the bigger profit margin.

(5.4) The optimal retail price charged by manufacturer 1 is always smaller than those charged by retailer 1 and retailer 2 , and the marginal profit obtained by manufacturer 1 from the online channel is also bigger than those earned by retailer 1 , retailer 2 , and manufacturer 2 . So, the online channel can deeply increase manufacturer 1's competition. Moreover, the competition between manufacturer l's online channel and retailer l's traditional channel makes retailer l's price in four models always higher than the prices of retailer 2 and manufacturer 1.

\section{Conclusions}

The objective of this article is to study the effects of dualchannel format on the supply chain competition and on the supply chain members' pricing decisions. Specifically, for two competing supply chains, can one supply chain increase its competition ability by introducing an online channel facing different bargaining structures? So, we consider two supply chains which compete in the same market with two substitutable products. Each supply chain includes one manufacturer and one retailer, and the two manufacturers produce two substitutable products. One of the two manufacturers is a traditional manufacturer who only sells his product through the traditional channel, while the other manufacturer has opened an online channel, so that he can sell his product directly through the online channel, or sells his product 


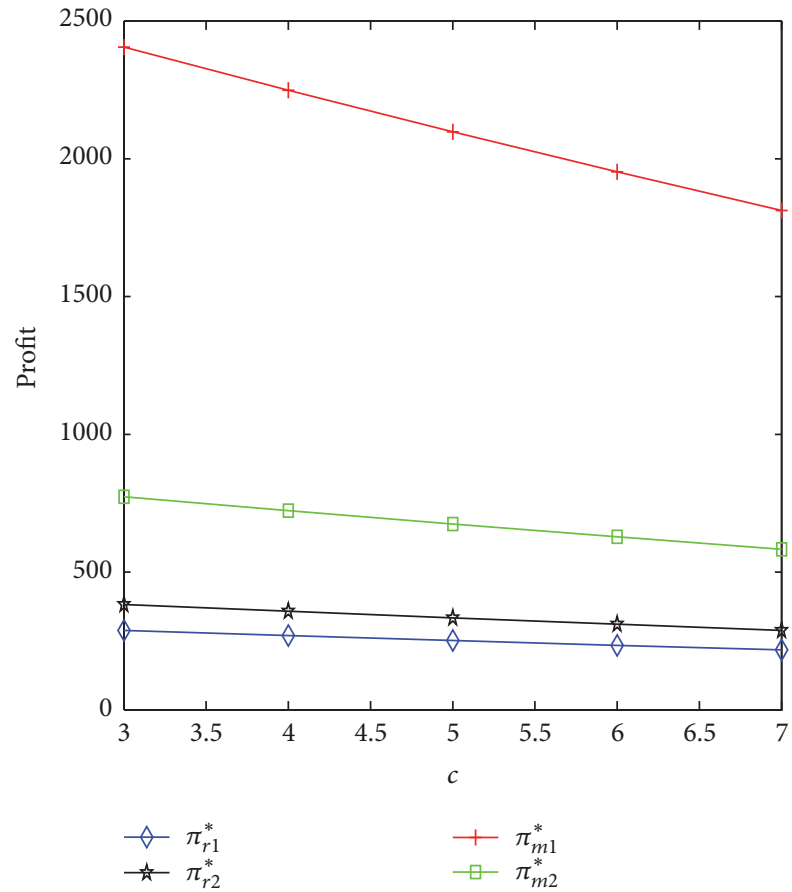

FIGURE 9: Changes of maximal profits with parameter $c$ in MOMT model.

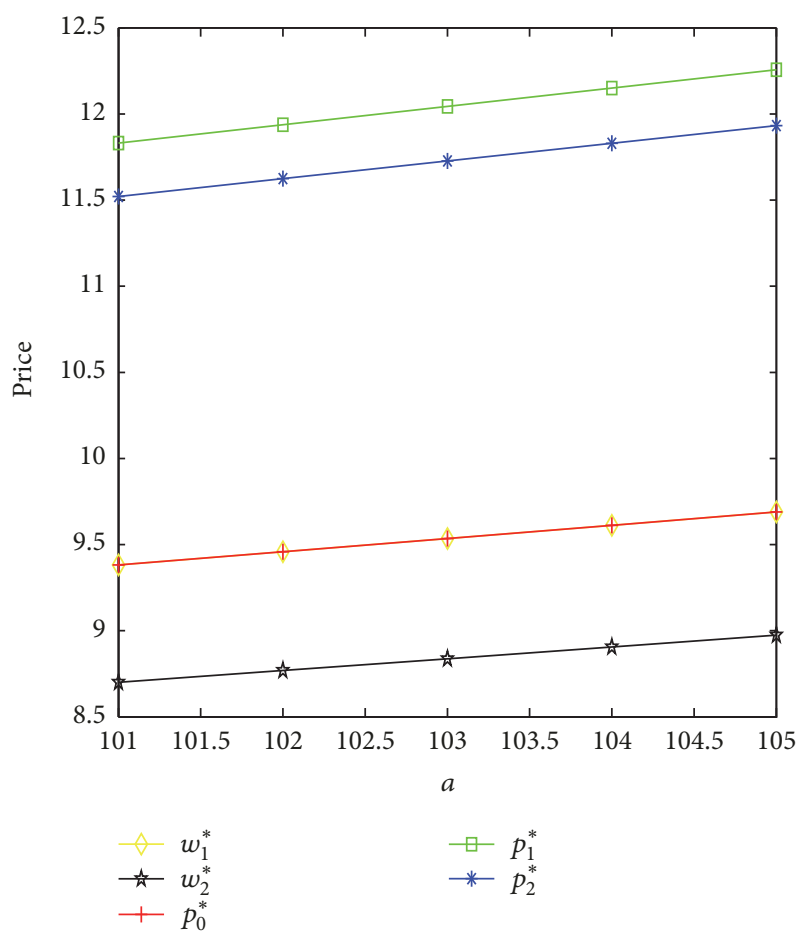

FIGURE 10: Changes of optimal prices with parameter $a$ in MOMT model.

through the traditional channel. We formulate four game models by considering different bargaining structures and get the optimal prices and maximal profits of all supply chain members. Through comparing and analyzing the equilibrium solutions with numerical approach, some new managerial

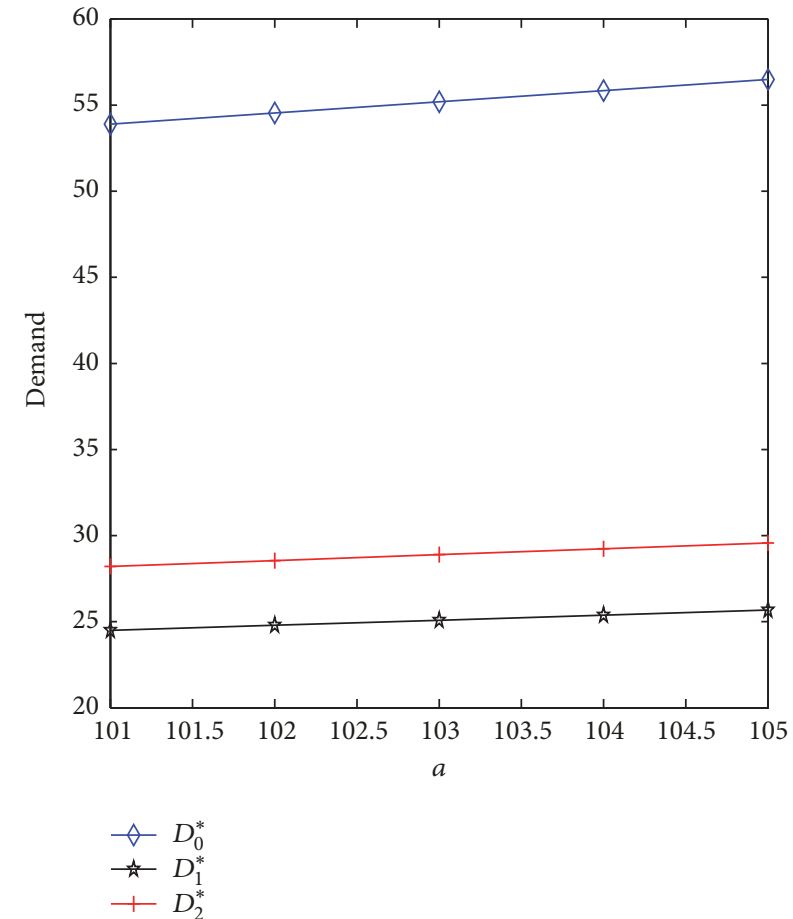

FIGURE 11: Changes of maximal demands with parameter $a$ in MOMT model.

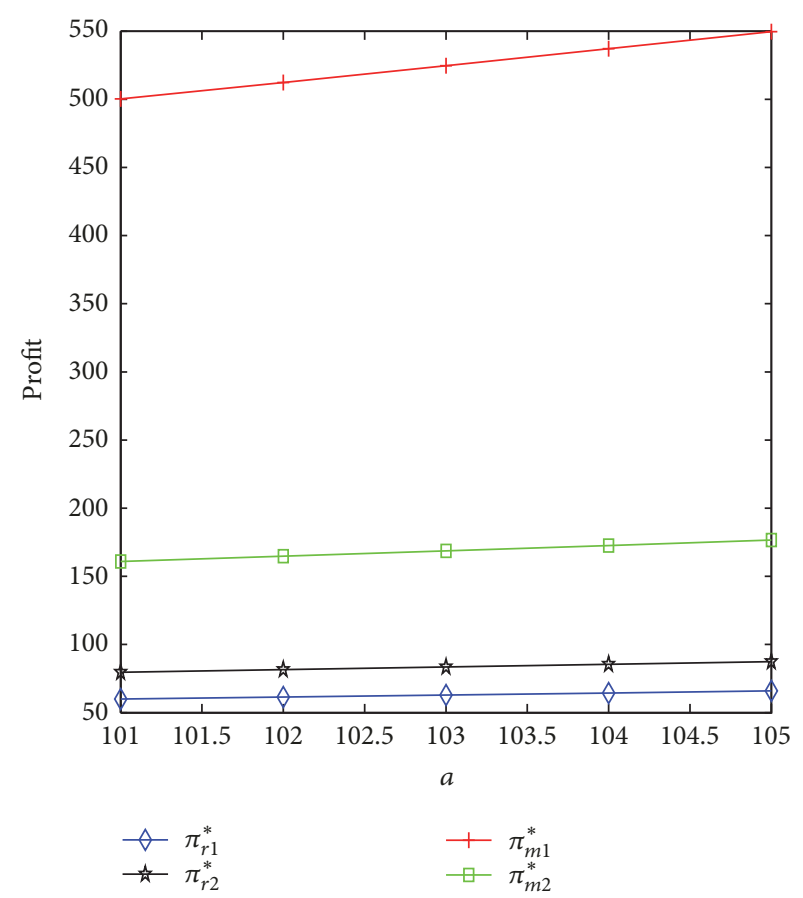

FIGURE 12: Changes of maximal profits with parameter $a$ in MOMT model.

insights are derived as follows: (1) manufacturer 1 can deeply strengthen its competition ability by adopting dual channel regardless of the two supply chains' bargaining structures. However, the online channel introduced by a manufacturer does not always benefit the manufacturer's retailer. (2) The optimal retail price charged by manufacturer 1 is always 
smaller than that charged by retailer 1 and retailer 2 , and the marginal profit obtained by manufacturer 1 from the online channel is also bigger than that earned by retailer 1 , retailer 2 , and manufacturer 2 .

However, our results are based upon some assumptions about the models of competing supply chains. Thus, several extensions to the analysis in this paper are possible. First, as opposed to the risk-neutral channel members considered in this paper, one could study the case where the channel members have different attitudes towards risk and could also examine the influence of their attitudes towards risk on individual decisions and profits. Second, this paper considers a case with deterministic-linear-demand function in a single period; one can study the case with other forms of demand function in stochastic/fuzzy multiple periods environment. Third, this article considers the case where only two supply chains compete in the market with two substitutable products; one can consider the case with $n(n \geq 3)$ supply chains competing in the market.

\section{Appendix}

\section{A. Notations for Decision Models}

$$
\begin{aligned}
& A_{1}=\frac{2\left(\beta_{0}+\beta_{1}+\beta_{3}\right)\left(\beta_{0}+\beta_{2}+\beta_{3}\right)}{4\left(\beta_{0}+\beta_{1}+\beta_{3}\right)\left(\beta_{0}+\beta_{2}+\beta_{3}\right)-\beta_{3}^{2}}, \\
& A_{2}=\frac{2 \beta_{1}\left(\beta_{0}+\beta_{2}+\beta_{3}\right)+\beta_{2} \beta_{3}}{4\left(\beta_{0}+\beta_{1}+\beta_{3}\right)\left(\beta_{0}+\beta_{2}+\beta_{3}\right)-\beta_{3}^{2}}, \\
& A_{3}=\frac{\beta_{3}\left(\beta_{0}+\beta_{2}+\beta_{3}\right)}{4\left(\beta_{0}+\beta_{1}+\beta_{3}\right)\left(\beta_{0}+\beta_{2}+\beta_{3}\right)-\beta_{3}^{2}}, \\
& A_{4}=\frac{2 a\left(\beta_{0}+\beta_{2}+\beta_{3}\right)+a \beta_{3}}{4\left(\beta_{0}+\beta_{1}+\beta_{3}\right)\left(\beta_{0}+\beta_{2}+\beta_{3}\right)-\beta_{3}^{2}}, \\
& A_{5}=\frac{\beta_{3}\left(\beta_{0}+\beta_{1}+\beta_{3}\right)}{4\left(\beta_{0}+\beta_{1}+\beta_{3}\right)\left(\beta_{0}+\beta_{2}+\beta_{3}\right)-\beta_{3}^{2}}, \\
& A_{6}=\frac{2 \beta_{2}\left(\beta_{0}+\beta_{1}+\beta_{3}\right)+\beta_{1} \beta_{3}}{4\left(\beta_{0}+\beta_{1}+\beta_{3}\right)\left(\beta_{0}+\beta_{2}+\beta_{3}\right)-\beta_{3}^{2}}, \\
& A_{7}=\frac{2 a\left(\beta_{0}+\beta_{1}+\beta_{3}\right)+a \beta_{3}}{4\left(\beta_{0}+\beta_{1}+\beta_{3}\right)\left(\beta_{0}+\beta_{2}+\beta_{3}\right)-\beta_{3}^{2}}, \\
& A_{8}=2\left(\beta_{3} A_{5}-\left(\beta_{0}+\beta_{1}+\beta_{3}\right) A_{1}\right) \text {, } \\
& A_{9}=\beta_{3} A_{6}-\left(\beta_{0}+\beta_{1}+\beta_{3}\right) A_{2}+\beta_{1}+\beta_{1} A_{1}+\beta_{2} A_{5} \text {, } \\
& A_{10}=\beta_{3} A_{1}-\left(\beta_{0}+\beta_{1}+\beta_{3}\right) A_{3} \text {, } \\
& A_{11}=c_{1}\left(\left(\beta_{3}+\beta_{2}\right) A_{5}-\left(\beta_{0}+\beta_{3}\right) A_{1}\right)-a+\left(\beta_{0}+\beta_{1}+\beta_{3}\right) A_{4}-\beta_{3} A_{7} \text {, } \\
& A_{13}=\beta_{1} A_{3}+\beta_{2} A_{1} \text {, } \\
& A_{12}=2\left(\beta_{1} A_{2}-\left(\beta_{0}+\beta_{1}+\beta_{2}\right)+\beta_{2} A_{6}\right) \text {, } \\
& A_{15}=\beta_{3} A_{1}-\left(\beta_{0}+\beta_{2}+\beta_{3}\right) A_{5} \text {, } \\
& A_{14}=c_{1}\left(\left(\beta_{3}+\beta_{2}\right) A_{6}-\left(\beta_{0}+\beta_{3}\right) A_{2}-\beta_{0}-\beta_{2}\right)-a-\beta_{1} A_{4}-\beta_{2} A_{7}, \\
& A_{16}=\beta_{3} A_{2}-\left(\beta_{0}+\beta_{2}+\beta_{3}\right) A_{6}+\beta_{2} \text {, } \\
& A_{17}=2\left(\beta_{3} A_{3}-\left(\beta_{0}+\beta_{2}+\beta_{3}\right) A_{1}\right) \text {, } \\
& A_{18}=c_{2}\left(\beta_{3} A_{3}-\left(\beta_{0}+\beta_{2}+\beta_{3}\right) A_{1}\right)-a-\beta_{3} A_{4}+\left(\beta_{0}+\beta_{2}+\beta_{3}\right) A_{7}, \\
& B_{1}=\frac{\beta_{3}\left(\beta_{0}+\beta_{1}+\beta_{2}\right)+\beta_{1} \beta_{2}}{\left(\beta_{0}+\beta_{1}+\beta_{2}\right)\left(\beta_{0}+\beta_{1}+\beta_{3}\right)-\beta_{1}^{2}},
\end{aligned}
$$




$$
\begin{aligned}
& B_{3}=\frac{\beta_{1} \beta_{3}+\beta_{2}\left(\beta_{0}+\beta_{1}+\beta_{3}\right)}{2\left(\beta_{0}+\beta_{1}+\beta_{2}\right)\left(\beta_{0}+\beta_{1}+\beta_{3}\right)-2 \beta_{1}^{2}}, \\
& B_{2}=\frac{\left(\beta_{0}+\beta_{1}+\beta_{2}\right) a+\beta_{1} a+\left(\left(\beta_{0}+\beta_{1}+\beta_{2}\right)\left(\beta_{0}+\beta_{3}\right)+\beta_{1}\left(\beta_{0}+\beta_{2}\right)\right) c_{1}}{2\left(\beta_{0}+\beta_{1}+\beta_{2}\right)\left(\beta_{0}+\beta_{1}+\beta_{3}\right)-\beta_{1}^{2}}, \\
& B_{4}=\frac{\left(\beta_{0}+\beta_{1}+\beta_{3}\right) a+\beta_{1} a+\left(\left(\beta_{0}+\beta_{1}+\beta_{3}\right)\left(\beta_{0}+\beta_{2}\right)+\beta_{1}\left(\beta_{0}+\beta_{3}\right)\right) c_{1}}{2\left(\beta_{0}+\beta_{1}+\beta_{2}\right)\left(\beta_{0}+\beta_{1}+\beta_{3}\right)-2 \beta_{1}^{2}}, \\
& B_{5}=\frac{\beta_{3}}{\beta_{0}+\beta_{2}+\beta_{3}}, \\
& B_{6}=\frac{\beta_{2} B_{3}}{\beta_{0}+\beta_{2}+\beta_{3}}-1 \text {, } \\
& B_{7}=\frac{\beta_{2} B_{4}+a}{\beta_{0}+\beta_{2}+\beta_{3}}+c_{2} \text {, } \\
& B_{8}=-4\left(\beta_{0}+\beta_{1}+\beta_{3}\right) \text {, } \\
& B_{9}=B_{1}\left(\beta_{0}+\beta_{1}+\beta_{3}\right)+2\left(\beta_{1} B_{3}+\beta_{3}\right) \text {, } \\
& B_{10}=B_{2}\left(\beta_{0}+\beta_{1}+\beta_{3}\right)+2\left(a+\beta_{1} B_{4}\right), \\
& B_{11}=\left(1-B_{6}\right) \beta_{3}-B_{5}\left(\beta_{2} B_{3}-\left(\beta_{0}+\beta_{2}+\beta_{3}\right)\right) \text {, } \\
& B_{12}=2\left(1-B_{6}\right)\left(\beta_{2} B_{3}-\left(\beta_{0}+\beta_{2}+\beta_{3}\right)\right) \text {, } \\
& B_{13}=\left(1-B_{6}\right)\left(a+\beta_{2} B_{4}\right)-B_{7}\left(\beta_{2} B_{3}-\left(\beta_{0}+\beta_{2}+\beta_{3}\right)\right) \text {, } \\
& E_{1}=\frac{\beta_{3}}{2\left(\beta_{0}+\beta_{2}+\beta_{3}\right)}, \\
& E_{2}=\frac{2 \beta_{2}\left(\beta_{0}+\beta_{1}+\beta_{3}\right)+\beta_{1} \beta_{3}}{2\left(\beta_{0}+\beta_{1}+\beta_{3}\right)\left(\beta_{0}+\beta_{2}+\beta_{3}\right)}, \\
& E_{3}=\frac{\beta_{3}^{2}-2\left(\beta_{0}+\beta_{1}+\beta_{3}\right)\left(\beta_{0}+\beta_{2}+\beta_{3}\right)}{2\left(\beta_{0}+\beta_{1}+\beta_{3}\right)\left(\beta_{0}+\beta_{2}+\beta_{3}\right)}, \\
& E_{4}=\frac{a \beta_{3}+2 a\left(\beta_{0}+\beta_{1}+\beta_{3}\right)}{2\left(\beta_{0}+\beta_{1}+\beta_{3}\right)\left(\beta_{0}+\beta_{2}+\beta_{3}\right)}+c_{2} \text {, } \\
& E_{5}=\frac{\beta_{1}^{2}-2\left(\beta_{0}+\beta_{1}+\beta_{2}\right)\left(\beta_{0}+\beta_{1}+\beta_{3}\right)}{\left(\beta_{0}+\beta_{1}+\beta_{3}\right)}, \\
& E_{6}=\beta_{2}+\frac{\beta_{1} \beta_{3}}{2\left(\beta_{0}+\beta_{1}+\beta_{3}\right)} \text {, } \\
& E_{7}=a+\frac{a \beta_{1}}{2\left(\beta_{0}+\beta_{1}+\beta_{3}\right)}+\frac{\left(\beta_{0}+\beta_{1}+\beta_{3}\right)\left(2\left(\beta_{0}+\beta_{2}\right)+\beta_{1}\right)-\beta_{1}^{2}}{2\left(\beta_{0}+\beta_{1}+\beta_{3}\right)} c_{1} \text {, } \\
& E_{8}=\frac{E_{1}\left(2\left(\beta_{0}+\beta_{1}+\beta_{3}\right)\left(\beta_{0}+\beta_{2}+\beta_{3}\right)-\beta_{3}^{2}\right)}{2\left(\beta_{0}+\beta_{1}+\beta_{3}\right)}+\frac{\beta_{3}\left(1-E_{3}\right)}{2}, \\
& E_{9}=\frac{E_{2}\left(2\left(\beta_{0}+\beta_{1}+\beta_{3}\right)\left(\beta_{0}+\beta_{2}+\beta_{3}\right)-\beta_{3}^{2}\right)}{2\left(\beta_{0}+\beta_{1}+\beta_{3}\right)}+\frac{\left(1-E_{3}\right)\left(\beta_{1} \beta_{3}+2 \beta_{2}\left(\beta_{0}+\beta_{1}+\beta_{3}\right)\right)}{2\left(\beta_{0}+\beta_{1}+\beta_{3}\right)}, \\
& E_{10}=\frac{\left(1-E_{3}\right)\left(\beta_{3}^{2}-2\left(\beta_{0}+\beta_{1}+\beta_{3}\right)\left(\beta_{0}+\beta_{2}+\beta_{3}\right)\right)}{\left(\beta_{0}+\beta_{1}+\beta_{3}\right)},
\end{aligned}
$$




$$
\begin{aligned}
& E_{11}=\frac{E_{4}\left(2\left(\beta_{0}+\beta_{1}+\beta_{3}\right)\left(\beta_{0}+\beta_{2}+\beta_{3}\right)-\beta_{3}^{2}\right)}{2\left(\beta_{0}+\beta_{1}+\beta_{3}\right)}+\frac{\left(1-E_{3}\right)\left(a \beta_{3}+2 a\left(\beta_{0}+\beta_{1}+\beta_{3}\right)\right)}{2\left(\beta_{0}+\beta_{1}+\beta_{3}\right)}, \\
& F_{1}=\frac{\beta_{3}\left(2 \beta_{1}^{2}-2\left(\beta_{0}+\beta_{1}+\beta_{2}\right)\left(\beta_{0}+\beta_{1}+\beta_{3}\right)\right)}{4\left(\beta_{0}+\beta_{2}+\beta_{3}\right) \beta_{1}^{2}+\beta_{1} \beta_{2} \beta_{3}+\left(\beta_{0}+\beta_{1}+\beta_{3}\right)\left(\beta_{2}^{2}-4\left(\beta_{0}+\beta_{2}+\beta_{3}\right)\left(\beta_{0}+\beta_{1}+\beta_{2}\right)\right)}, \\
& F_{2}=\frac{\left(\beta_{0}+\beta_{2}+\beta_{3}\right)\left(2 \beta_{1}^{2}-2\left(\beta_{0}+\beta_{1}+\beta_{2}\right)\left(\beta_{0}+\beta_{1}+\beta_{3}\right)\right)}{4\left(\beta_{0}+\beta_{2}+\beta_{3}\right) \beta_{1}^{2}+\beta_{1} \beta_{2} \beta_{3}+\left(\beta_{0}+\beta_{1}+\beta_{3}\right)\left(\beta_{2}^{2}-4\left(\beta_{0}+\beta_{2}+\beta_{3}\right)\left(\beta_{0}+\beta_{1}+\beta_{2}\right)\right)}, \\
& F_{3}=\frac{a\left(2 \beta_{1}^{2}-2\left(\beta_{0}+\beta_{1}+\beta_{2}\right)\left(\beta_{0}+\beta_{1}+\beta_{3}\right)\right)-\beta_{1} \beta_{2} a-\left(\beta_{0}+\beta_{1}+\beta_{3}\right) \beta_{2} a}{4\left(\beta_{0}+\beta_{2}+\beta_{3}\right) \beta_{1}^{2}+\beta_{1} \beta_{2} \beta_{3}+\left(\beta_{0}+\beta_{1}+\beta_{3}\right)\left(\beta_{2}^{2}-4\left(\beta_{0}+\beta_{2}+\beta_{3}\right)\left(\beta_{0}+\beta_{1}+\beta_{2}\right)\right)} \\
& -\frac{\beta_{2} c_{2}\left(\beta_{1}\left(\beta_{0}+\beta_{3}\right)+\left(\beta_{0}+\beta_{2}\right)\left(\beta_{0}+\beta_{1}+\beta_{3}\right)\right)}{4\left(\beta_{0}+\beta_{2}+\beta_{3}\right) \beta_{1}^{2}+\beta_{1} \beta_{2} \beta_{3}+\left(\beta_{0}+\beta_{1}+\beta_{3}\right)\left(\beta_{2}^{2}-4\left(\beta_{0}+\beta_{2}+\beta_{3}\right)\left(\beta_{0}+\beta_{1}+\beta_{2}\right)\right)}, \\
& F_{4}=\frac{2\left(\beta_{0}+\beta_{2}+\beta_{3}\right) F_{1}-\beta_{3}}{\beta_{2}}, \\
& F_{5}=\frac{\left(\beta_{0}+\beta_{2}+\beta_{3}\right)\left(2 F_{2}-1\right)}{\beta_{2}}, \\
& F_{6}=\frac{2\left(\beta_{0}+\beta_{2}+\beta_{3}\right) F_{3}-a}{\beta_{2}}, \\
& F_{7}=\frac{2\left(\beta_{0}+\beta_{1}+\beta_{2}\right) F_{4}-\beta_{2} F_{1}-\beta_{1}}{\beta_{1}}, \\
& F_{8}=\frac{2\left(\beta_{0}+\beta_{1}+\beta_{2}\right) F_{5}-\beta_{2} F_{2}}{\beta_{1}}, \\
& F_{9}=\frac{2\left(\beta_{0}+\beta_{1}+\beta_{2}\right) F_{6}-\beta_{2} F_{3}-a-c_{1}\left(\beta_{0}+\beta_{2}\right)}{\beta_{1}}, \\
& F_{10}=2\left(1-F_{7}\right)\left(\beta_{1} F_{4}+\beta_{3} F_{1}-\left(\beta_{0}+\beta_{1}+\beta_{3}\right)\right), \\
& F_{11}=\left(1-F_{7}\right)\left(\beta_{1} F_{5}+\beta_{3} F_{2}\right)-F_{8}\left(\beta_{1} F_{4}+\beta_{3} F_{1}-\left(\beta_{0}+\beta_{1}+\beta_{3}\right)\right), \\
& F_{12}=\left(1-F_{7}\right)\left(\beta_{1} F_{6}+\beta_{3} F_{3}+a\right)-F_{9}\left(\beta_{1} F_{4}+\beta_{3} F_{1}-\left(\beta_{0}+\beta_{1}+\beta_{3}\right)\right) \text {, } \\
& F_{13}=\beta_{3}+\beta_{2} F_{4}-\left(\beta_{0}+\beta_{2}+\beta_{3}\right), \\
& F_{14}=2\left(\beta_{2} F_{5}-\left(\beta_{0}+\beta_{2}+\beta_{3}\right) F_{2}\right) \text {, } \\
& F_{15}=a+\beta_{2} F_{6}-\left(\beta_{0}+\beta_{2}+\beta_{3}\right) F_{3}-c_{2}\left(\beta_{2} F_{5}-\left(\beta_{0}+\beta_{2}+\beta_{3}\right) F_{2}\right) \text {. }
\end{aligned}
$$

\section{B. Conditions for Model Parameters}

To ensure that the various profit expressions will be well behaved and possess a unique optimum, similar to Tsay and Agrawal [24], we impose the following conditions on the parameters:

$$
\begin{gathered}
A_{17}<0, \\
A_{8} A_{12}-A_{9}^{2}>0, \\
B_{8}<0, \\
B_{12}<0,
\end{gathered}
$$$$
A_{8}<0,
$$$$
F_{10}<0 \text {, }
$$$$
A_{12}<0 \text {, }
$$$$
F_{14}<0 \text {. }
$$ 


\section{Proofs of Propositions}

Proof of Proposition 1. It follows from (2) and (3) that the firstand second-order derivatives of $\pi_{r 1}$ to $p_{1}$ and $\pi_{r 2}$ to $p_{2}$ can be shown as

$$
\begin{aligned}
\frac{\partial \pi_{r 1}}{\partial p_{1}}= & -2\left(\beta_{0}+\beta_{1}+\beta_{3}\right) p_{1}+\beta_{3} p_{2}+\beta_{1} p_{0} \\
& +\left(\beta_{0}+\beta_{1}+\beta_{3}\right) w_{1}+a, \\
\frac{\partial \pi_{r 2}}{\partial p_{2}}= & -2\left(\beta_{0}+\beta_{2}+\beta_{3}\right) p_{2}+\beta_{3} p_{1}+\beta_{2} p_{0} \\
& +\left(\beta_{0}+\beta_{2}+\beta_{3}\right) w_{2}+a, \\
\frac{\partial^{2} \pi_{r 1}}{\partial p_{1}^{2}}= & \frac{\partial^{2} \pi_{r 2}}{\partial p_{2}^{2}}=-2\left(\beta_{0}+\beta_{2}+\beta_{3}\right)<0 .
\end{aligned}
$$

It follows from (C.3) that $\pi_{r i}$ is concave in $p_{i}, i=1,2$. Therefore, by setting (C.1) and (C.2) to zero and solving them simultaneously, we obtain (9).

From (6)-(9), the first-order partial derivatives of $\pi_{m 1}$ to $w_{1}$ and $p_{0}$ and the first-order derivative of $\pi_{m 2}$ to $w_{2}$ can be shown as

$$
\begin{aligned}
& \frac{\partial \pi_{m 1}}{\partial w_{1}}=A_{8} w_{1}+A_{9} p_{0}+A_{10} w_{2}+A_{11} \\
& \frac{\partial \pi_{m 1}}{\partial p_{0}}=A_{9} w_{1}+A_{12} p_{0}+A_{13} w_{2}+A_{14} \\
& \frac{\partial \pi_{m 2}}{\partial w_{2}}=A_{15} w_{1}+A_{16} p_{0}+A_{17} w_{2}+A_{18}
\end{aligned}
$$

Then we get

$$
\begin{aligned}
\frac{\partial^{2} \pi_{m 2}}{\partial w_{2}^{2}} & =A_{17} \\
\frac{\partial^{2} \pi_{m 1}}{\partial w_{1}^{2}} & =A_{8} \\
\frac{\partial^{2} \pi_{m 1}}{\partial p_{0}^{2}} & =A_{12} \\
\frac{\partial^{2} \pi_{m 1}}{\partial w_{1} \partial p_{0}} & =\frac{\partial^{2} \pi_{m 1}}{\partial p_{0} \partial w_{1}}=A_{9} .
\end{aligned}
$$

From (C.5) and assumption (B.1), $\pi_{m 1}$ is jointly concave in $w_{1}$ and $p_{0}$ and $\pi_{m 2}$ is concave in $w_{2}$. Therefore, by setting (C.4) to zero and solving them simultaneously, we obtain (10). Using (9)-(10), Proposition 1 can be obtained.

Proof of Proposition 2. Without loss of generality, let $m_{i}$ be the margin of product $i$ enjoyed by the retailer $i$; namely,

$$
p_{i}=w_{i}+m_{i}
$$

where $m_{i}>0, i=1,2$.
From (6), (7), and (C.6), the first-order partial derivatives of $\pi_{m 1}$ to $w_{1}$ and $p_{0}$ and the first-order derivative of $\pi_{m 2}$ to $w_{2}$ can be shown as

$$
\begin{aligned}
\frac{\partial \pi_{m 1}}{\partial w_{1}}= & -\left(\beta_{0}+\beta_{1}+\beta_{3}\right) w_{1}+2 \beta_{1} p_{0} \\
& -\left(\beta_{0}+\beta_{1}+\beta_{3}\right) p_{1}+\beta_{3} p_{2}+a \\
& +\left(\beta_{0}+\beta_{3}\right) c_{1}, \\
\frac{\partial \pi_{m 1}}{\partial p_{0}}= & \beta_{1} w_{1}-2\left(\beta_{0}+\beta_{1}+\beta_{2}\right) p_{0}+\beta_{1} p_{1}+\beta_{2} p_{2} \\
& +a+\left(\beta_{0}+\beta_{2}\right) c_{1}, \\
\frac{\partial \pi_{m 2}}{\partial w_{2}}= & \beta_{2} p_{0}-\left(\beta_{0}+\beta_{2}+\beta_{3}\right) w_{2}+\beta_{3} p_{1} \\
& -\left(\beta_{0}+\beta_{2}+\beta_{3}\right) p_{2}+a \\
& +\left(\beta_{0}+\beta_{2}+\beta_{3}\right) c_{2} .
\end{aligned}
$$

Then we get

$$
\begin{gathered}
\frac{\partial^{2} \pi_{m 1}}{\partial w_{1}^{2}}=-2\left(\beta_{0}+\beta_{1}+\beta_{3}\right), \\
\frac{\partial^{2} \pi_{m 1}}{\partial p_{0}^{2}}=-2\left(\beta_{0}+\beta+\beta_{2}\right), \\
\frac{\partial^{2} \pi_{m 1}}{\partial w_{1} \partial p_{0}}=\frac{\partial^{2} \pi_{m 1}}{\partial p_{0} \partial w_{1}}=2 \beta_{1}, \\
\frac{\partial^{2} \pi_{m 2}}{\partial w_{2}^{2}}=-2\left(\beta_{0}+\beta_{2}+\beta_{3}\right) .
\end{gathered}
$$

Using (C.10) and (C.11), we know that $\pi_{m 2}$ is concave in $w_{2}$ and $\pi_{m 1}$ is jointly concave in $w_{1}$ and $p_{0}$. Therefore, by setting (C.7)-(C.9) to zero and solving them simultaneously, we obtain (14).

It follows from (4), (5), and (14) that the first- and secondorder derivatives of $\pi_{r 1}$ to $p_{1}$ and $\pi_{r 2}$ to $p_{2}$ can be shown as

$$
\begin{aligned}
& \frac{\partial \pi_{r 1}}{\partial p_{1}}=B_{8} p_{1}+B_{9} p_{2}+B_{10} \\
& \frac{\partial \pi_{r 2}}{\partial p_{2}}=B_{11} p_{1}+B_{12} p_{2}+B_{13} \\
& \frac{\partial^{2} \pi_{r 1}}{\partial p_{1}^{2}}=B_{8} \\
& \frac{\partial^{2} \pi_{r 2}}{\partial p_{2}^{2}}=B_{12} .
\end{aligned}
$$

It follows from (C.14) and assumption (B.2) that $\pi_{\mathrm{r} i}$ is concave in $p_{i}, i=1,2$. Therefore, by setting (C.12) and (C.13) to zero and solving them simultaneously, we obtain (15) and (16). With (14)-(16), one can easily see that Proposition 2 holds. 
Proof of Proposition 3. Given earlier decisions $p_{2}, w_{1}$, and $p_{0}$ made by retailer 2 and manufacturer 1 , respectively, we can have the first-order derivative of $\pi_{r 1}$ to $p_{1}$ and the firstorder derivative of $\pi_{m 2}$ to $w_{2}$ as shown in (C.1) and (C.9). Therefore, by setting (C.1) and (C.9) to zero and solving them simultaneously, we obtain (21).

It follows from (5), (6), (21), and (C.6) that the first-order partial derivatives of $\pi_{m 1}$ to $w_{1}$ and $p_{0}$ and the first-order derivative of $\pi_{r 2}$ to $p_{2}$ can be shown as

$$
\begin{aligned}
\frac{\partial \pi_{m 1}}{\partial w_{1}}= & -\left(\beta_{0}+\beta_{1}+\beta_{3}\right) w_{1}+\beta_{1} p_{0}+\frac{\beta_{3}}{2} p_{2} \\
& +\frac{a+c_{1}\left(\beta_{0}+\beta_{3}\right)}{2}, \\
\frac{\partial \pi_{m 1}}{\partial p_{0}}= & \beta_{1} w_{1}+E_{5} p_{0}+E_{6} p_{2}+E_{7}, \\
\frac{\partial \pi_{r 2}}{\partial p_{2}}= & E_{8} w_{1}+E_{9} p_{0}+E_{10} p_{2}+E_{11},
\end{aligned}
$$

where $E_{5}, E_{6}, \ldots, E_{11}$ are constants defined in Appendix A. Then we get

$$
\begin{aligned}
\frac{\partial^{2} \pi_{m 1}}{\partial w_{1}^{2}} & =-\left(\beta_{0}+\beta_{1}+\beta_{3}\right)<0, \\
\frac{\partial^{2} \pi_{m 1}}{\partial p_{0}^{2}} & =E_{5}<0, \\
\frac{\partial^{2} \pi_{m 1}}{\partial w_{1} \partial p_{0}} & =\frac{\partial^{2} \pi_{m 1}}{\partial p_{0} \partial w_{1}}=\beta_{1}, \\
\frac{\partial^{2} \pi_{r 2}}{\partial p_{2}^{2}} & =E_{10}<0 .
\end{aligned}
$$

With (C.19), we can know that $\pi_{m 1}$ is jointly concave in $w_{1}$ and $p_{0}$ and $\pi_{r 2}$ is concave in $p_{2}$. By setting (C.15) to zero and solving them, simultaneously, we obtain (22).

From (21)-(22), one can easily have (23) and (24). Therefore, Proposition 3 holds.

Proof of Proposition 4. Given earlier decisions $w_{2}$ and $p_{1}$ made by manufacturer 2 and retailer 1 , respectively, we can have the first-order partial derivatives of $\pi_{m 1}$ to $w_{1}$ and $p_{0}$ and the first-order derivative of $\pi_{r 2}$ to $p_{2}$ as shown in (C.7), (C.8), and (C.2). Therefore, by setting (C.7), (C.8), and (C.2) to zero and solving them simultaneously, we obtain (26).

It follows from (4), (7), and (26) that the first-order derivative of $\pi_{r 1}$ to $p_{1}$ and the first-order partial derivatives of $\pi_{m 2}$ to $w_{2}$ and $\tau$ can be shown as

$$
\begin{gathered}
\frac{\partial \pi_{r 1}}{\partial p_{1}}=F_{10} p_{1}+F_{11} w_{2}+F_{12} \\
\frac{\partial \pi_{m 2}}{\partial w_{2}}=F_{13} p_{1}+F_{14} w_{2}+F_{15}
\end{gathered}
$$

where $F_{10}, F_{11}, \ldots, F_{15}$ are constants defined in Appendix A.
Then we get

$$
\begin{gathered}
\frac{\partial^{2} \pi_{r 1}}{\partial p_{1}^{2}}=F_{10}, \\
\frac{\partial^{2} \pi_{m 2}}{\partial w_{2}^{2}}=F_{14} .
\end{gathered}
$$

Using (C.19) and assumption (B.3), we know that $\pi_{r 1}$ is concave in $p_{1}$ and $\pi_{m 2}$ is concave in $w_{2}$. Therefore, by setting (C.17) and (C.18) to zero and solving them simultaneously, we obtain (27) and (28). From (26)-(28), we can obtain Proposition 4.

\section{Conflicts of Interest}

The authors declare that there are no conflicts of interest regarding the publication of this paper.

\section{Acknowledgments}

The authors gratefully acknowledge the support of National Natural Science Foundation of China (Research Fund no. 71301116).

\section{References}

[1] A. A. Tsay and N. Agrawal, "Modeling conflict and coordination in multi-channel distribution systems: a review," in Handbook of Quantitative Supply Chain Analysis, D. Simchi-Levi, D. Wu, and M. Shen, Eds., vol. 74 of International Series in Operations Research \& Management Science, pp. 557-606, Springer US, Boston, Mass, USA, 2004.

[2] J. Chen, H. Zhang, and Y. Sun, "Implementing coordination contracts in a manufacturer Stackelberg dual-channel supply chain," Omega , vol. 40, no. 5, pp. 571-583, 2012.

[3] D. Q. Yao and J. J. Liu, "Competitive pricing of mixed retail and e-tail distribution channels," Omega , vol. 33, no. 3, pp. 235-247, 2005.

[4] G. W. Hua, S. Y. Wang, and T. C. E. Cheng, "Price and lead time decisions in dual-channel supply chains," European Journal of Operational Research, vol. 205, no. 1, pp. 113-126, 2010.

[5] A. Dumrongsiri, M. Fan, A. Jain, and K. Moinzadeh, "A supply chain model with direct and retail channels," European Journal of Operational Research, vol. 187, no. 3, pp. 691-718, 2008.

[6] K. D. Cattani, W. G. Gilland, and J. M. Swaminathan, "Coordinating traditional and internet supply chains," in Handbook of Quantitative Supply Chain Analysis, D. Simchi-Levi, D. Wu, and M. Shen, Eds., vol. 74 of International Series in Operations Research \& Management Science, pp. 643-677, Springer US, Boston, Mass, USA, 2004.

[7] K.-Y. Chen, M. Kaya, and Ö. Özer, "Dual sales channel management with service competition," Manufacturing and Service Operations Management, vol. 10, no. 4, pp. 654-675, 2008.

[8] G. Cai, Z. G. Zhang, and M. Zhang, "Game theoretical perspectives on dual-channel supply chain competition with price discounts and pricing schemes," International Journal of Production Economics, vol. 117, no. 1, pp. 80-96, 2009.

[9] R. Batarfi, M. Y. Jaber, and S. Zanoni, "Dual-channel supply chain: a strategy to maximize profit," Applied Mathematical Modelling, vol. 40, no. 21-22, pp. 9454-9473, 2016. 
[10] W. Huang and J. M. Swaminathan, "Introduction of a second channel: implications for pricing and profits," European Journal of Operational Research, vol. 194, no. 2, pp. 258-279, 2009.

[11] M. Khouja, S. Park, and G. Cai, "Channel selection and pricing in the presence of retail-captive consumers," International Journal of Production Economics, vol. 125, no. 1, pp. 84-95, 2010.

[12] F. Schneider and D. Klabjan, "Inventory control in multichannel retail," European Journal of Operational Research, vol. 227, no. 1, pp. 101-111, 2013.

[13] J. Q. Yang, X. M. Zhang, H. Y. Fu, and C. Liu, "Inventory competition in a dual-channel supply chain with delivery lead time consideration," Applied Mathematical Modelling, vol. 42, pp. 675-692, 2017.

[14] D. Wu, O. Baron, and O. Berman, "Bargaining in competing supply chains with uncertainty," European Journal of Operational Research, vol. 197, no. 2, pp. 548-556, 2009.

[15] E. J. Anderson and Y. Bao, "Price competition with integrated and decentralized supply chains," European Journal of Operational Research, vol. 200, no. 1, pp. 227-234, 2010.

[16] M. Trivedi, "Distribution channels: An extension of exclusive retailership," Management Science, vol. 44, no. 7, pp. 896-909, 1998.

[17] J. Wei and J. Zhao, "Pricing and remanufacturing decisions in two competing supply chains," International Journal of Production Research, vol. 53, no. 1, pp. 258-278, 2015.

[18] T. W. McGuire and R. Staelin, "An industry equilibrium analysis of downstream vertical integration," Marketing Science, vol. 2, no. 2, pp. 161-191, 1983.

[19] A. T. Coughlan, "Competition and cooperation in marketing channel choice: theory and application," Marketing Science, vol. 4, no. 2, pp. 110-129, 1985.

[20] S. C. Choi, "Price competition in a channel structure with a common retailer," Marketing Science, vol. 10, no. 4, pp. 271-296, 1991.

[21] S. C. Choi, "Price competition in a duopoly common retailer channel," Journal of Retailing, vol. 72, no. 2, pp. 117-134, 1996.

[22] E. Lee and R. Staelin, "Vertical strategic interaction: implications for channel pricing strategy," Marketing Science, vol. 16, no. 3, pp. 185-207, 1997.

[23] J. Zhao, W. Tang, and J. Wei, "Pricing decision for substitutable products with retail competition in a fuzzy environment," International Journal of Production Economics, vol. 135, no. 1, pp. 144-153, 2012.

[24] A. A. Tsay and N. Agrawal, "Channel dynamics under price and service competition," Manufacturing and Service Operations Management, vol. 2, no. 4, pp. 372-391, 2000.

[25] B. K. Mishra and S. Raghunathan, "Retailer- vs. Vendormanaged inventory and brand competition," Management Science, vol. 50, no. 4, pp. 445-457, 2004.

[26] Y. C. Chen, S.-C. Fang, and U.-P. Wen, "Pricing policies for substitutable products in a supply chain with Internet and traditional channels," European Journal of Operational Research, vol. 224, no. 3, pp. 542-551, 2013. 


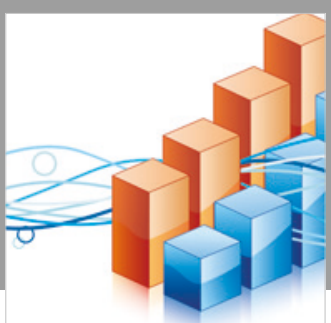

Advances in

Operations Research

\section{-n-m}
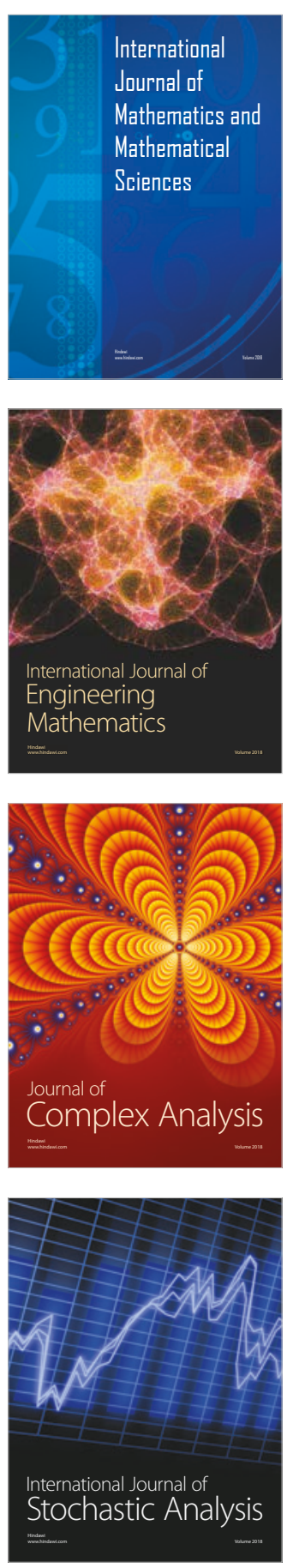
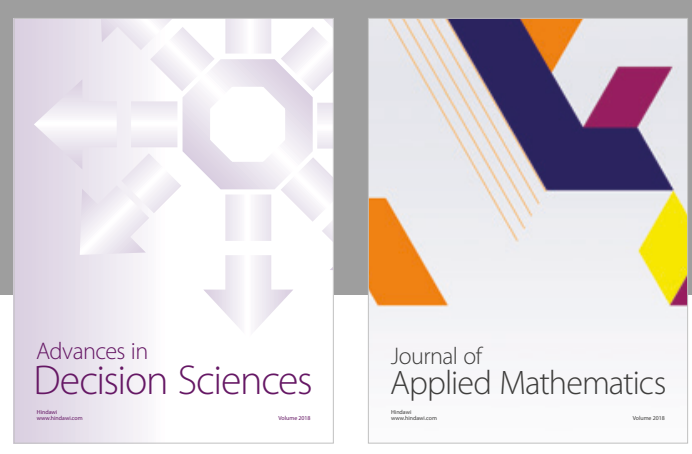

Journal of

Applied Mathematics
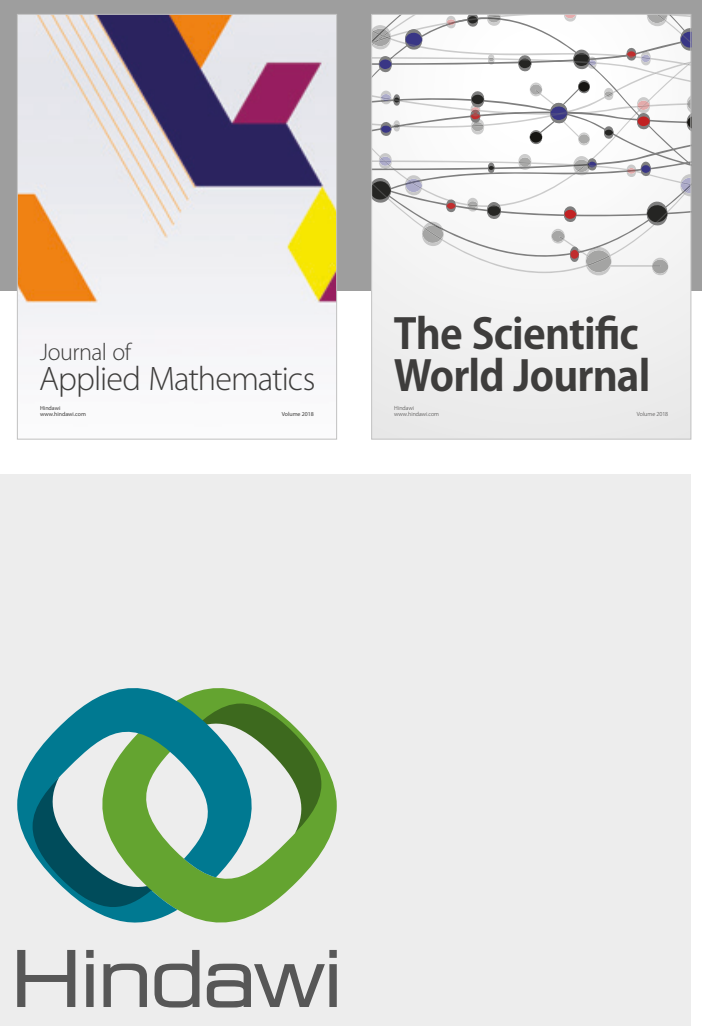

Submit your manuscripts at

www.hindawi.com

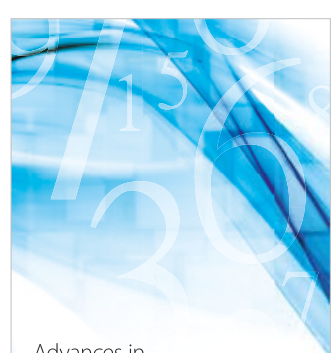

Advances in
Numerical Analysis
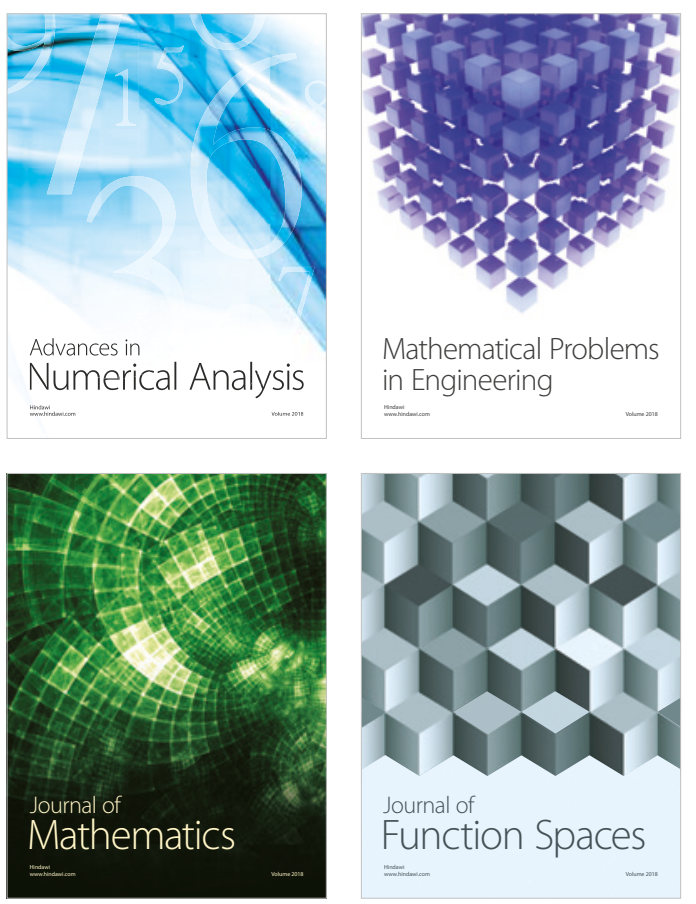

Mathematical Problems in Engineering

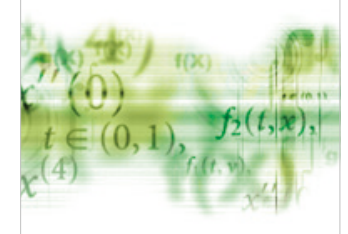

International Journal of

Differential Equations

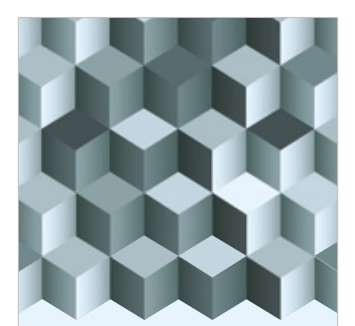

Journal of

Function Spaces

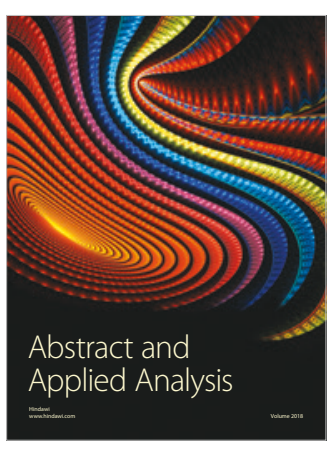

The Scientific

World Journal

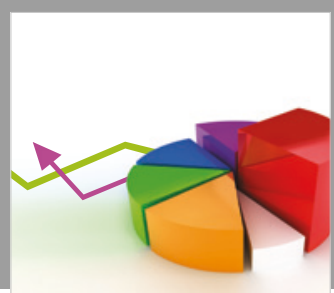

Journal of

Probability and Statistics
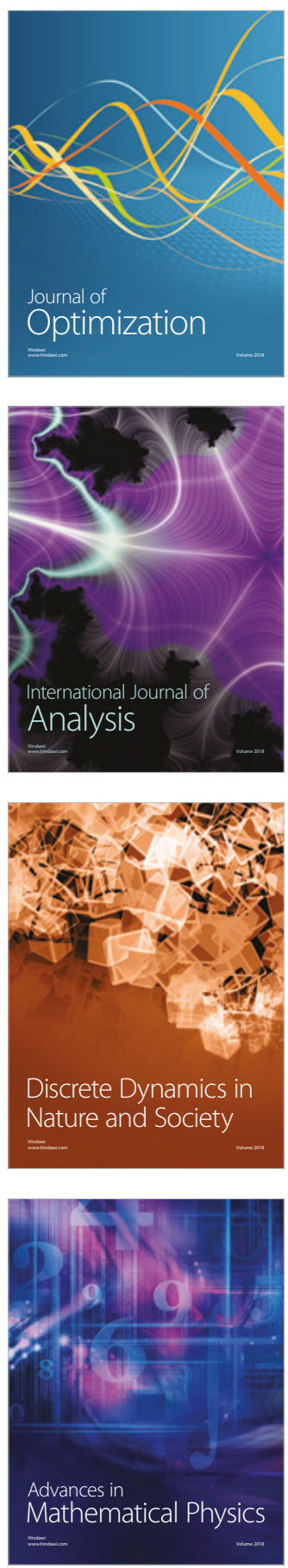